\title{
Non-model model organisms
}

\author{
James J. Russell', Julie A. Theriot ${ }^{2 *}$, Pranidhi Sood ${ }^{3}$, Wallace F. Marshall ${ }^{3 *}$, Laura F. Landweber ${ }^{4}$, Lillian Fritz-Laylin ${ }^{5}$, \\ Jessica K. Polka ${ }^{6}$, Snezhana Oliferenko ${ }^{7,8}$, Therese Gerbich ${ }^{9}$, Amy Gladfelter ${ }^{9}$, James Umen ${ }^{10}$, Magdalena Bezanilla ${ }^{5}$, \\ Madeline A. Lancaster ${ }^{11}$, Shuonan He ${ }^{12}$, Matthew C. Gibson ${ }^{12,13}$, Bob Goldstein ${ }^{14}$, Elly M. Tanaka ${ }^{15}$, \\ Chi-Kuo Hu${ }^{16}$ and Anne Brunet ${ }^{16,17}$
}

\begin{abstract}
Model organisms are widely used in research as accessible and convenient systems to study a particular area or question in biology. Traditionally only a handful of organisms have been widely studied, but modern research tools are enabling researchers to extend the set of model organisms to include less-studied and more unusual systems. This Forum highlights a range of 'non-model model organisms' as emerging systems for tackling questions across the whole spectrum of biology (and beyond), the opportunities and challenges, and the outlook for the future.
\end{abstract}

\section{Introduction-model organisms for understanding biology \\ Wallace F. Marshall}

The transition in biology from description to mechanistic understanding during the 20th century was due in large part to a conscious decision to employ model organisms. The idea of a model organism is that if one wants to study a particular aspect of biology, it makes sense to employ a simple, tractable organism that facilitates experimental work. Bacteriophage, bacteria, corn, and yeast revealed most of what we know about basic molecular biology of the central dogma, while flies, worms, Arabidopsis, and mice played a similar role in the study of development. The choice of these systems was not arbitrary-they typically were chosen because they were smaller, simpler, and faster growing than more complex organisms such as humans or trees. The term "model organism" was used to indicate a simplified, tractable system that could be used to study a larger

\footnotetext{
* Correspondence: theriot@stanford.edu; Wallace.marshall@ucsf.edu 2 Departments of Biochemistry and of Microbiology \& Immunology, Howard Hughes Medical Institute Stanford University, Stanford, CA 94305, USA ${ }^{3}$ Department of Biochemistry \& Biophysics, University of California San Francisco, 600 16th St, San Francisco, CA 94158, USA

Full list of author information is available at the end of the article
}

theme of biology, and indicated not so much a feature of the system itself, as an attitude on the part of the researcher. The "phage group" was not primarily interested in how bacteriophage worked as an end in itself, but rather as a means to a larger end of understanding gene regulation. Bacteriophage were simply a convenient model for studying the bigger question. An experiment could be done hundreds or thousands of times more quickly and cheaply using bacteriophage than human cells, so it is hardly surprising that research in simpler systems rapidly outpaced work in humans. Likewise, flies have been studied for a century not so much because so many people find flies themselves interesting, but because flies made genetic analysis of development easy and fast. In some cases the simplest systems are so simple that they lack key features of interest-for example, bacteria and bacteriophage do not employ the full range of regulatory mechanisms that eukaryotes do-requiring the use of more complex model systems such as yeast for the study of chromatin, meiosis, and other eukaryoticspecific parts of the central dogma. The term model organism was used to describe these systems and conveyed the meaning of "an organism that is inherently convenient to study a particular area of biology".

Because these model organisms were so convenient, and made progress so rapid, researchers flocked to use them. This led to the development of tools and resources specifically for these organisms. Resources include infrastructure, such as databases and strain collections, as well as molecular toolkits and extensive collections of techniques and methods, accumulated over the years by legions of researchers. The development of these resources happened for model organisms because so many people were working on them, and because they were already so convenient. Why spend time developing methods for a less convenient system? As a result, model organisms began to outpace other systems not only in terms of their inherent convenience, but also in terms of the availability of infrastructure to 
study them. This difference was highlighted by the early genome projects, which for obvious reasons focused on model organisms. Once the yeast, Drosophila and Caenorhabditis elegans genomes were available, it made even less sense to work on anything else. The gap in methodology and resources between the select few model organisms and everything else led to a gradual linguistic shift in how the term "model organism" was understood, so that now many people, when they say model organism, use it not in its original sense, but instead in the sense of "an organism for which a wealth of tools and resources exist".

But it was always appreciated that the major model organisms, while convenient for studying many aspects of biology, weren't necessarily the best systems for all possible questions. None of the standard models were that good at regenerating, for example, and the extremely sparse coverage of biodiversity represented by standard models meant that evolutionary questions had to be handled very carefully. Model organisms were known for many of these hard-to-reach areas of biology, but they were only model organisms in the original sense (convenient for the study of a biological process) but not in the newer sense (possessing infrastructure and resources). Fortunately, the continual decrease in cost of genomic sequencing has now made it feasible to determine a genome sequence for these classic but under-supported models. Even if, as is often the case, established genome centers refuse to take on a new organism, citing lack of a large community of researchers, it is now possible for individual labs to assemble their own sequences. Once a genome sequence is in hand, many methods, such as RNA sequencing, can be immediately applied, and other methods such as CRISPR come into range for development. As a result, there has been an explosion of interest in extending the set of model organisms to include both classic systems long known to be excellent models for particular areas of biology, as well as completely novel systems that have never been explored experimentally but which pose fascinating challenges for mechanistic understanding. We will refer to organisms that are models in the original sense, but not yet in the newer sense, as "non-model model organisms" (NMMO).

The present Forum describes the opportunities created by several such non-model model organisms, as well as the challenges faced in developing methods and resources to study them. The use of genomic information is a common thread, as is the emphasis on Biology writ large. The organisms discussed here were picked up because of their inherent advantages for studying key biological questions, including pattern formation (diatoms, Stentor), branching morphogenesis (Physcomitrella, Ashbya), regeneration (Stentor, axolotl), and aging (killifish). The diversity of life addressable using NMMO provides new opportunities for studying the evolution of multicellular life (Volvox), body plans (Nematostella, tardigrades, cerebral organoids), and cell biological processes (Oxytricha, Naegleria, Physcomitrella, fission yeasts). Other questions now being asked using NMMO are more on the sci-fi end of the spectrum, including suspended animation (tardigrades, killfish), phase transitions (Ashbya), and nanobiotechnology ( $\mathrm{R}$ bodies, diatoms). All of these examples have one thing in common-exploiting the unique biological features of a special organism to address questions of general importance. These organisms aren't being studied because they are weird, or because of a fondness for biodiversity, but because they make it easier to ask central questions about biology that have remained unanswered to this day.

\section{Diatoms are ready for their close-up}

\section{James J. Russell and Julie A. Theriot}

Diatoms are unicellular eukaryotes abundant in aquatic environments. Their photosynthesis represents a significant fraction of global primary productivity and oceanic carbon sequestration [1]. Among cell biologists, however, diatoms are best known for their extraordinary and beautifully nano-patterned cell walls, made of silicon dioxide-that is, glass [2] (Fig. 1a). Many of us first encountered diatoms in the form of isolated glass cell walls, known as frustules, mounted on slides used as a measure of resolving power, for dark field alignment of microscopes, or in scanning electron micrographs invoking alien-like architecture (Fig. 1b-d). Their exquisite complexity is reminiscent of high-magnification images of snowflakes; however, the diatom frustules are created by genetically encoded developmental programs, and as such are highly reproducible and characteristic for many of the 10,000 to 100,000 estimated species [3]. The variety found even in a single environmental sample can be sufficient to inspire endlessly fascinating but very tiny art [4]. How do these cells design and build their glass houses?

A wide variety of organisms, including protozoa such as radiolarians, many vascular plants, and even some metazoans such as the hexatinellid sponges, have independently developed the ability to precipitate silicon dioxide from soluble silicon compounds (for example silicic acid) in water [5], in a process analogous to the more familiar biomineralization processes used by humans and other vertebrates to precipitate calcium phosphate in our bony skeletons, or by mollusks to make shells using calcium carbonate. In all these cases, the inorganic material is carefully organized and patterned by active cellular processes, and organic molecules are intimately intertwined with the minerals in 


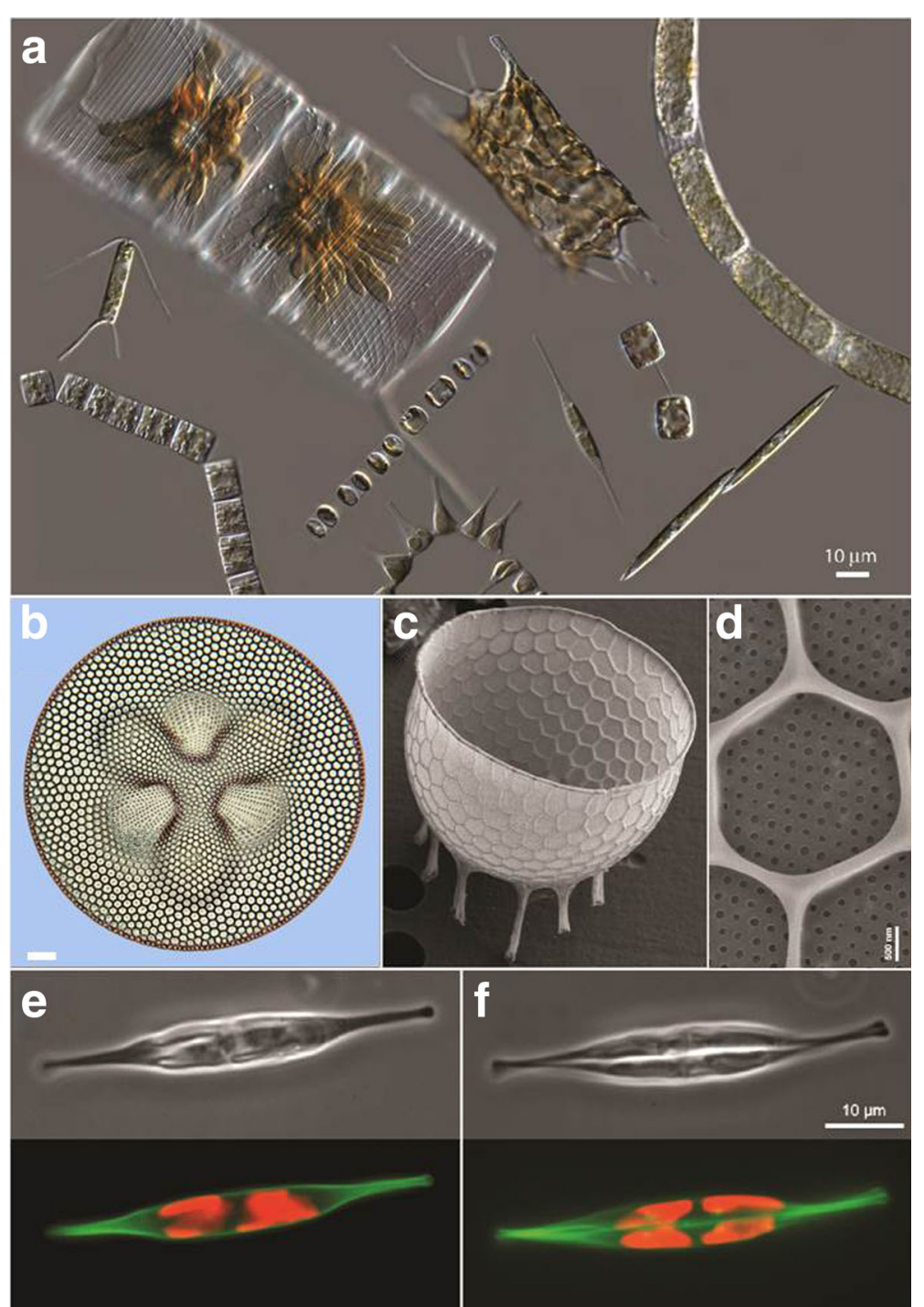

Fig. 1. Images of various diatom species. a Differential interference contrast images of (clockwise from top left): Striatella unipunctata, Odontella sp., Stephanopyxis turris, Pseudo-nitzschia sp., Thalassiosira sp., Cylindrotheca sp., Asterionellopsis glacialis, Skeletonema costatum, Grammatophora oceanica, and Chaetoceros sp. Images are courtesy of Colleen Durkin and reproduced from [324]. b Differential interference contrast image of Coscinodiscus excavatus, image courtesy of Robert Lavigne. c-d Scanning electron micrographs of Stephanopyxis turris theca (c) and nanoscale features (d), images courtesy of Mark Webber. $\mathbf{e}-\mathbf{f}$ Cylindrotheca fusiformis before cell division (e) and during cell division (f). Top: phase contrast. Bottom: polymerized silica labeled with HCK-123 dye (green) and endogenous chlorophyll fluorescence (red). Scale bar in b $20 \mu \mathrm{m}$

ways that enhance their material properties and determine their characteristic larger-scale architectures $[6,7]$. For diatoms, the fundamental building block of the glass frustule is a near-spherical silicon dioxide nodule about $40 \mathrm{~nm}$ in diameter [8]. These precipitated nodules can be formed from soluble silicic acid by several characterized diatom proteins, notably the silaffins [9]. However, the mechanisms by which the diatom cells assemble these simple structural precursors into highly regular nanoscale and microscale patterns in the valve of the frustule are largely unknown. While subcellular microtubule and actin distributions show intriguing correlations with some frustule features [10] and pharmacological disruption of microtubules can lead to defects in pattern determination [11], there is essentially no molecular information available about the mechanisms of pattern formation.

Why do we know so little about the cell biological mechanisms of these lovely organisms? One major barrier has been the lack of useful classic genetics in any diatom species. All characterized diatoms grow vegetatively with diploid genomes, making random mutagenesis strategies difficult, and while individuals of many species have been observed to undergo a sexual cycle in 
nature [2], they have proved to be shy about reliably mating in the test tube. Despite the lack of classic genetics, several recent advances have made possible the examination of cell biological questions in diatoms using reverse genetic and post-genomic approaches. The first complete genome sequences for two widely cultivated diatoms, Thalassiosira pseudonana and Phaeodactylum tricornutum, were released in 2004 and 2008 , respectively $[12,13]$, and several additional sequenced diatom genomes have been annotated and made publicly available, belonging primarily to species difficult to culture [14, 15]. Although diatoms are phylogenetically distant from the opisthokonts, including fungi and metazoans, where we have developed our most complete understanding of the mechanisms of regulation of eukaryotic gene expression, nevertheless the structure of diatom genomes appears to be sufficiently similar to our familiar model species that it has been possible to generate robustly annotated genomes, with support from diatom EST libraries and RNA-sequencing data.

Critically, several model diatom species have been shown to be genetically transformable by either electroporation [16] or bacterial conjugation [17], and capable of expressing tagged transgenic protein constructs, including GFP fused to integral components of the glass frustule [18]. In addition, CRISPR-Cas9 genome editing has recently become feasible in model diatoms $[19,20]$, and several diatom viruses have been sequenced [21] which may provide useful resources for building tools as so many animal viruses have done before them. Owing to the relative ease of adapting these modern genetic tools to diatoms, several labs are engaging additional tools with promising results, including proximity proteomics, live cell microscopy, and super-resolution fluorescence microscopy [22].

What is next for the study of pattern formation in diatoms? Unfortunately, the two model diatoms whose genomes have been robustly annotated are not among the more charismatic of this clade. They are both small and structurally simple; indeed Phaeodactylum tricornutum is poorly silicified and does not produce clear nanopatterns, and the tiny valve of Thalassiosira pseudonana displays only a rudimentary silica pore structure. A few more annotated genomes for a few elaborately structured but still rapidly growing laboratory strains would be particularly useful; one enticing candidate is Cylindrotheca fusiformis, a large $(\sim 50 \mu \mathrm{m}$ length), motile diatom with gracious long arms and a dramatic helical twist along its valvar (cell division) axis (Fig. 1e). C. fusiformis is amenable to electroporation-mediated genetic transformation (unpublished data). In addition to the intrinsic value of diatoms as a case for studying pattern formation and biomineralization, diatoms have also attracted attention as sources for large-scale biomolecule production (including lipids for fuel or nutrition) [23], and further development of molecular methods for diatoms could enable genetic optimization for this purpose. Diatoms are easy to grow and wondrous to observe, and now is an ideal time to apply modern approaches to reexamine the ancient mystery of how diatoms achieve their nanoscale elegance.

\section{Stentor coeruleus as a model for single-cell regeneration}

Pranidhi Sood and Wallace F. Marshall

Individual cells can exhibit a great deal of cellular complexity in the organization of subcellular features and organelles. These subcellular patterns must be established and maintained to ensure a cell functions properly-for example, the apico-basal polarity of epithelial cells is required for them to correctly organize in sheets [24]. Cells are not small and amorphous, therefore, but can display complex and invariable internal organization. In fact, some even rival the size and complexity of multicellular embryos. How is morphological complexity created and regulated within a single membrane bound sac of cytoplasm?

Understanding how analogously complex structures arise in multicellular organisms formed the basis of the field of developmental biology. To study these problems before the availability of genetic tools, early researchers took advantage of systems that could regenerate, for example, the planarian flatworm. Similarly, studying the regeneration of cells can provide a window into the origins of cell geometry by decoupling assembly of structures from the normal growth processes in the cell. Historically, the analysis of regeneration in cells was in large part carried out using the giant ciliate Stentor coeruleus (Stentor) as an experimental system (Fig. 2). Stentor is a freshwater pond organism, notable for its bright blue coloration and the fact that a single cell can grow to be well over a millimeter in length. Each cell has an invariable, complex anatomy with an oral apparatus at one end, a holdfast at the other, and longitudinal stripes of blue pigment, separated by rows of cilia subtended by microtubule bundles, running down the length of the cell.

Stentor has many advantages for the study of regeneration at the single-cell level. First, it has unrivalled abilities to heal wounds, allowing the cell to recover from massive perturbations. For example, if a cell is bisected, each half will regenerate a normal cell [25]. The ability to sustain and recover from very large wounds is accompanied by the ability to graft pieces back together [26]. Such cellular scale "cut-and-paste" experiments are reminiscent of those that drove the field of experimental embryology. A comprehensive review of the experimental surgical work in Stentor was provided by Tartar [27]. An equally important feature of Stentor is 

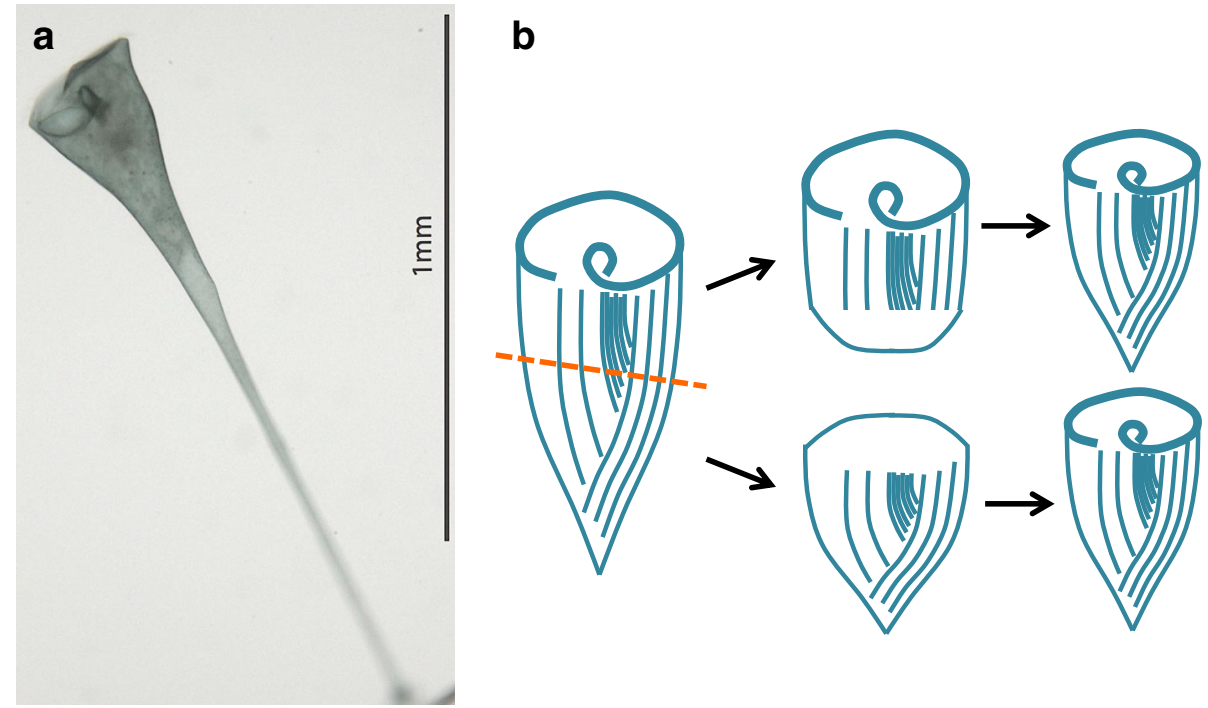

Fig. 2. Single-cell regeneration in Stentor coeruleus a A living Stentor cell. The oral apparatus, located towards the upper left of the image, is a large ring of cilia that collects food particles from the surrounding pond water. At the other end of the cell, a holdfast attaches the cell to the surface of pond plants. $\mathbf{b}$ Regeneration after bisection of a Stentor cell. The panel on the left shows the longitudinal strips of blue pigment that serve as markers for cellular pattern. When a Stentor cell is cut in half with a glass needle, as indicated by the dotted orange line, each half initially heals its wounds to prevent cytoplasm from leaking out (middle panels) and then within approximately one day, regenerates a complete cell (right panel), with the anterior half regenerating a new holdfast, and the poster half regenerating a new oral apparatus. Both halves are able to regenerate because the cell contains a long polyploid macronucleus running down the length of the cell, such that when a cell is cut, both halves retain many copies of the genome

the fact that its prominent organelles provide a clearly visible, built-in coordinate system. For example, a cell's entire surface is covered with visible features including long, oriented blue pigment stripes. These provide a frame of reference to determine if a cell has been correctly re-formed or if different parts of the cell are in the correct relative positions. Without these naturally occurring fiducial markers, it would be far more difficult to assess the progress of regeneration. It is known that the nucleus $[27,28]$ and transcription [29-32] are required for most regeneration processes in Stentor. However, there have been comparatively few molecular studies of regeneration in Stentor, owing in part to the challenges of growing large quantities. Stentor divides with a doubling time of several days, and it can take a long time to grow biochemically useful quantities.

Modern genomic technologies remove the need for growing huge numbers of cells and these tools can potentially shed light on the molecular mechanisms of regeneration. The key pre-requisite is to have the genome sequence. This was a major challenge in developing Stentor as a model system, because genome centers and sequencing programs proved unwilling to sequence an organism that didn't already have a large community of researchers studying it. In the end, we took a DIY approach, sequencing and assembling the genome in our own lab in collaboration with the DeRisi lab at UCSF, and then enlisting a team of experts to analyze the resulting genome. Through teamwork, we were recently able to publish the first Stentor genome [33].

With the Stentor genome in hand, we can begin to decipher the molecular networks behind cellular level regeneration, using techniques such as RNA-seq. We know that transcription is a key requirement for regeneration from foundational biochemical studies [29-32, 34], though specific transcripts driving regeneration were not identified. Also, there is evidence that transcripts synthesized during regeneration can become physically associated with newly formed organelles [32, 35], suggesting that RNA localization might play a role in patterning the cell as it does in the Drosophila melanogaster embryo. In the lab, we have recently developed an RNAi methodology for Stentor [36] that will allow us to functionally test the role of any genes that appear to be specifically induced during regeneration.

We expect that our molecular studies of regeneration and re-patterning in Stentor will reveal fundamental principles of how cells generate and regulate morphology, a general phenomenon relevant to the survival of all living systems. Cancer cells, for example, are marked by their loss of subcellular organization and recent studies have linked pathways that regulate polarity to those that suppress tumors [37]. How an individual cell establishes and maintains its subcellular organization is therefore a vital area of study in the initiation of tumorigenesis. Additionally, these studies could inform future 
technology development ranging from novel regenerative therapies that reactivate pathways in damaged cells to the creation of self-healing cellular robots.

\section{Life with 16,000 chromosomes: Oxytricha as a model system to study genome biology, epigenetic inheritance, and somatic differentiation}

\section{Laura F. Landweber}

The unicellular eukaryote Oxytricha with its extreme genomic architecture, provides a model system for many studies, including chromosome biology, post-zygotic development, epigenetics, and genome rearrangement. Oxytricha is a ciliated protist, and like other ciliate genera, including Stentor (see the preceding section from Sood and Marshall in this Forum) and the classic models Tetrahymena and Paramecium, Oxytricha shares the feature of nuclear dimorphism-the coexistence of two types of nuclei in one cell. The archival micronucleus is mostly transcriptionally silent but houses the complete diploid germline genome, which is large at over $500 \mathrm{Mb}$ on at least 75 chromosomes [38], and it produces haploid micronuclei for cell mating. The second type of nucleus, the somatic macronucleus, is a highly differentiated organelle devoted to gene expression. It develops from a copy of the new zygotic micronucleus after mating. Hence, nuclear differentiation in Oxytricha offers a microcosm of animal development in a unicellular model, as though development progresses to a sophisticated two-cell stage, with differentiated germline and soma, but without cell division. This results in a single protist cell with multiple nuclei. Additionally, some ciliate cells contain more than one nucleus of either type.

The process of forming a new macronucleus involves massive DNA elimination, rearrangement, and amplification [39]. Remarkably, approximately one-fifth of all $O x y$ tricha gene loci are scrambled in the germline [38]. These loci require a combination of translocation and/or inversion of DNA segments, in addition to DNA deletion, to assemble the expressed macronuclear versions (Fig. 3d). The combination of removal of nearly all intergenic DNA and loss of all satellites and transposons results in a somatic genome comprising over 16,000 tiny chromosomes that average approximately $3 \mathrm{~kb}$, as well as a much smaller genome size (approximately $50 \mathrm{Mb}$ ) [40]. Macronuclear chromosomes lack centromeres but are capped with their own telomeres and telomere binding proteins, and thus classically Oxytricha was one of the first model systems for studies of telomeres and their associated proteins [41, 42]. Amplification of these "nanochromosomes" to an average copy number of $\sim 1900$ in the macronucleus [39] creates a DNA-rich and physically enormous (10-30 micron) macronucleus [43] (Fig. 3c).

A phenomenal genome editor, Oxytricha reorganizes its zygotic genome by stitching together over 200,000 germline DNA segments, requiring a nearly equal number of programmed DNA breakage and joining events [38]. These are accompanied by RNA-guided DNA repair [44]. Noncoding RNA molecules are at the heart of orchestrating all these complex events, with long, noncoding, maternal RNA transcripts of the previous generation's MAC genome supplying templates for chromosome rearrangements [44, 45] and small RNAs marking the specific germline regions to be retained in the new somatic genome [46]. Therefore, Oxytricha provides a paragon for studies of DNA and chromosome dynamics, noncoding RNA-chromosome interactions, DNA breakage, recombination, and repair, and transposon participation [47]. The much reduced size of Oxytricha's somatic nanochromosomes also makes them a unique platform for basic studies of chromatin biology (Beh et al., unpublished data) as well as gene regulation, genome annotation, and gene discovery [48].

The cytoplasmic mixing that occurs during mating (Fig. 3d), coupled to the fact that the cytoplasm and cell surface material of exconjugant cells explicitly derive from the parental cells, make ciliates excellent model organisms to study epigenetic inheritance (reviewed in [49]). RNA molecules are among the contents that can be directly passed on from parent to exconjugant daughter cell, and RNA-mediated transgenerational inheritance has been demonstrated via injection of foreign long or small RNAs that reprogram genome rearrangement pathways [44, 46]. These approaches for RNA-guided gene editing, facilitated by the natural machinery in the cell, also provide tools for creating somatic gene knockouts or fusion genes [50]. For example, the programmed retention of short genomic regions that interrupt reading frames [46] can introduce premature stop codons and lead to the construction of laboratory strains (that can be stored as frozen cysts) with an inability to express a gene that is normally found in the macronucleus. Additional tool development is underway and still more is needed, for example, to permit parallel screens, but Oxytricha is emerging as a powerful and unique model system to probe features of complex eukaryotic cells and chromatin within the confines of a single cell.

\section{Naegleria gruberi: one cell with two extreme forms of motility}

Lillian Fritz-Laylin

Organisms from across the eukaryotic tree rely on two predominant forms of cell motility-crawling and swimming [51]. Each of these modes of locomotion arises from the basic characteristics of one of two conserved cytoskeletal systems: flagella used for cell swimming derive their power strokes from the sliding of stiff microtubules, while crawling motility is driven by the expansion and contraction of dynamic actin networks. The 

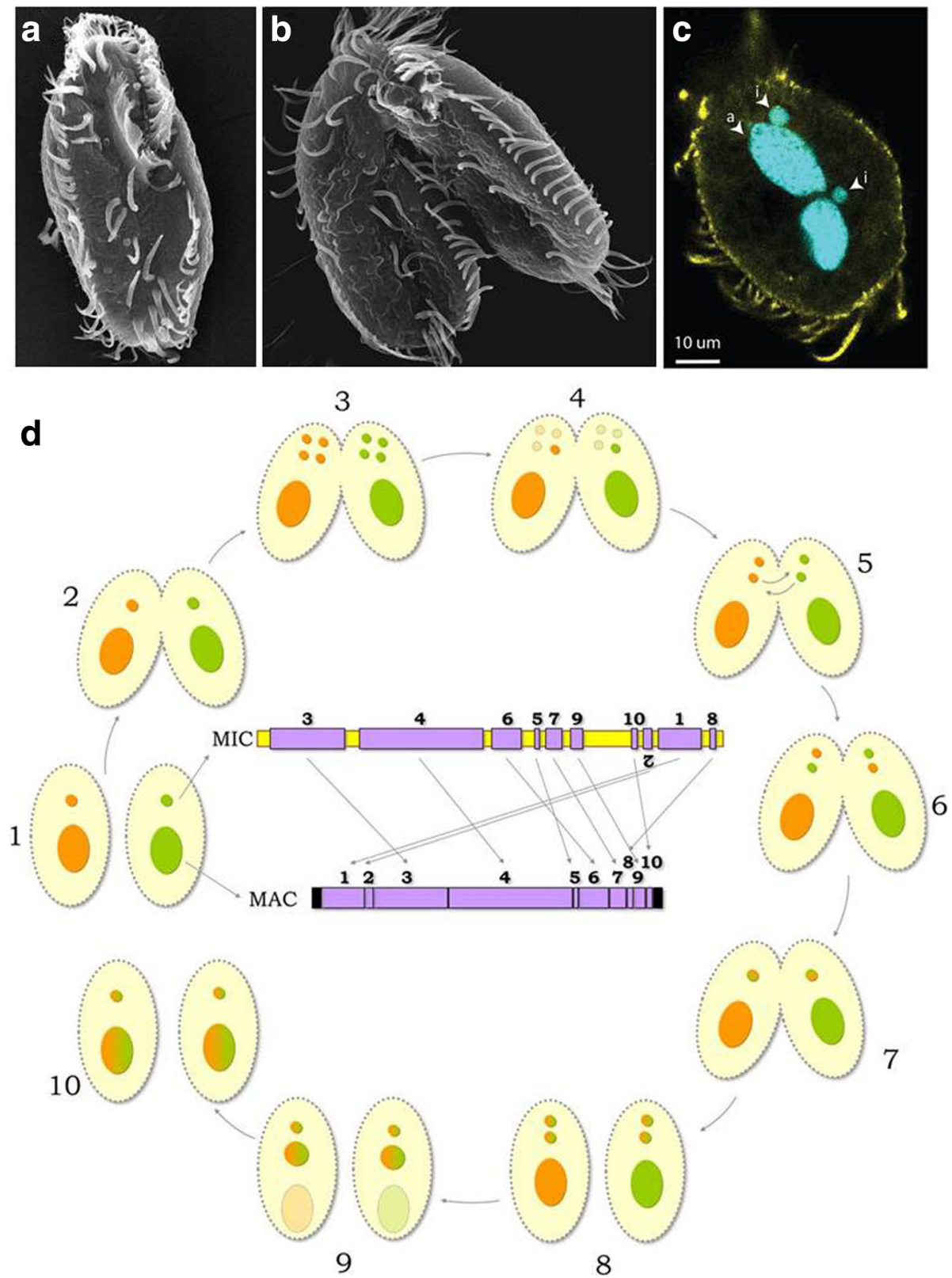

Fig. 3. Oxytricha as a model system to study genome biology, epigenetic inheritance, and somatic differentiation. $\mathbf{a}-\mathbf{c}$ Single $(\mathbf{a}, \mathbf{c})$ and mating $(\mathbf{b})$ Oxytricha cells. Blue indicates DNA; Yellow is tubulin, highlighting the cilia. i = micronucleus, a = macronucleus. Image in (a) courtesy of National Human Genome Research Institute, (b) courtesy of Robert Hammersmith, Ball State University and (c) courtesy of Wenwen Fang and reproduced from [325]. d The sexual life cycle of Oxytricha trifallax and rearrangement of scrambled genes, reproduced from [47]. All vegetative cells (stages 1 and 10) contain one (bi-lobed) macronucleus (MAC) and two micronuclei (MIC). The two MIC are genetically identical, but for simplicity we show only one here. (2) When starved, two cells of compatible mating types partially fuse to initiate conjugation. Cell fusion occurs soon after mixing of mating types. (3) Both vegetative micronuclei in each partner enter meiosis I. (4) One product from each meiosis I is promoted to meiosis II, and one of the four meiosis II products is promoted to a post-meiotic mitosis. (5) The sister products of one mitosis develop into gametic nuclei: a posterior stationary and an anterior migratory nucleus. This happens in both partners, such that both cells emerge with identical zygotic genotypes after the exchanged migratory nucleus fuses with the retained stationary nucleus (6), resulting in ( 7 two genetically identical exconjugant cells. (8) The newly formed zygotic nucleus divides twice: one daughter nucleus is destroyed, two become the new micronuclei, and (9) the parental macronucleus in each partner cell degrades, leaving telomere-to-telomere RNA transcripts behind to guide rearrangement [44, 45]. One zygotic nucleus differentiates into the new macronucleus. This cycle takes approximately $48-60 \mathrm{~h}$. Shown inside the circle are representative MIC and MAC versions of a scrambled gene. Retained DNA segments in purple; deleted DNA regions, including flanking DNA, in yellow; numbered segments correspond to the order in the expressed MAC version; segment 2 is inverted; telomeres are shown as black bars at the ends of the MAC chromosome 
noninfectious Naegleria gruberi (Naegleria) takes on two extremely different forms during its lifecycle: an amoeba that crawls using actin, and a flagellate that swims with two flagella (Fig. 4). The rapid differentiation between these forms makes Naegleria a prime model for understanding both types of cell motility $[52,53]$.

Naegleria amoebae crawl and divide without any observed cytoplasmic microtubules [53, 54]. Not only does Naegleria undergo closed mitosis (the mitotic spindle is always contained within the nuclear envelope), but the barrel-shaped mitotic spindle lacks centrioles [54] and is thought to be built from divergent tubulin expressed prior to mitosis and degraded after the completion of cytokinesis [55]. Therefore, and remarkably, all cellular functions except mitosis are likely achieved without microtubules-including crawling at speeds topping 120 microns per minute [56]. This makes Naegleria the fastest crawling cell that I am aware of, at least twice as fast as fish keratocytes, Dictyostelium discoideum, and human neutrophils [57-59]. Chemical inhibitor data from other organisms suggest that rapid actin-based cell migration may not require microtubules [60, 61], and Naegleria provides biologically relevant corroboration of this hypothesis. Furthermore, there is a growing appreciation that there are multiple modes of cell migration, each driven by distinct molecular mechanisms [62-64]. Unpublished data clearly indicate that Naegleria, like $D$. discoideum and some human cells $[65,66]$, migrates both by using actin-filled pseudopods (a mode we call alphamotility) and by blebbing (a delamination of the plasma membrane from the underlying actin cortex) (Fig. 4).

The differentiation of Naegleria from crawling amoebae to swimming flagellates involves assembling an entire microtubule cytoskeleton de novo, including two basal bodies (centrioles), the two flagella (cilia) that they pattern, and an entire cortical microtubule array [53, 67-71], as well as coordinating this new cytoskeleton with the preexisting actin cytoskeleton. The process of differentiation includes transcribing and translating all of the microtubule cytoskeletal components-including tubulin-yet takes only 60-90 minutes [53, 67, 69, 72-74].

Differentiation is easily synchronized, with $>90 \%$ of cells assembling basal bodies de novo within a 5-10-minute window [54, 67, 71]. (In contrast, mammalian cells take on the order of 24 hours to assemble centrioles de novo, typically after large experimental perturbations [75-77].) Recent evidence indicates that only one basal body is formed de novo, with a second in quick succession by mentored (previously "templated") assembly [78]. The speed and synchrony of Naegleria differentiation makes it

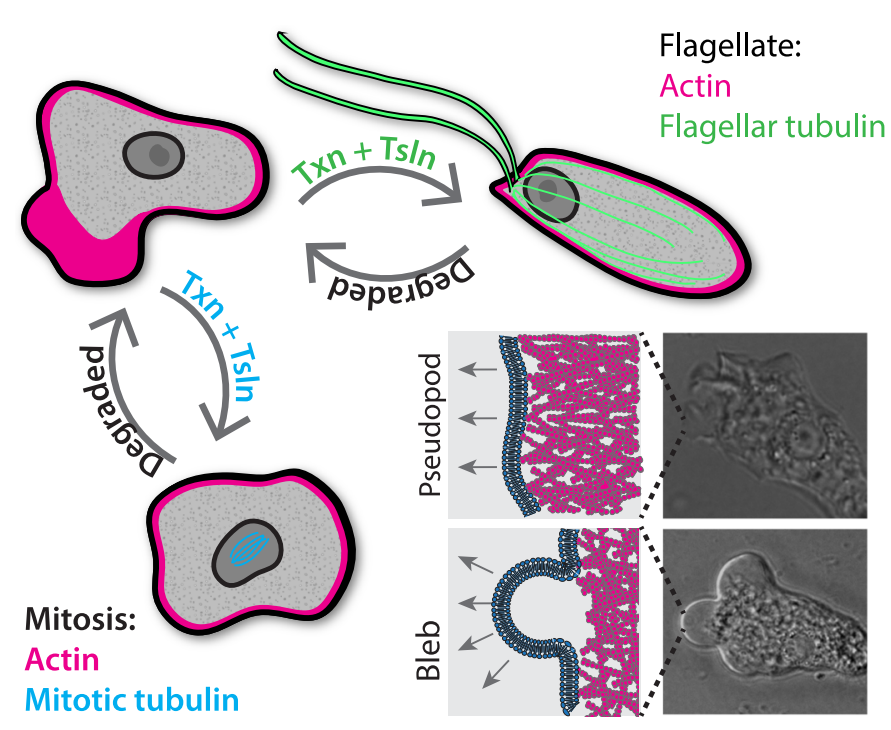

Fig. 4. Naegleria gruberi cells undergo a dramatic transformation between crawling amoebae and swimming flagellates, assembling an entire microtubule cytoskeleton along the way. The crawling amoebae (top left) lack cytoplasmic microtubules, but use their actin cytoskeleton (pink) to crawl with two types of protrusions (insets): actin-filled pseudopods and cytoplasm-filled spheres called blebs that appear after delamination of the cell membrane from the underlying actin cortex. Amoebae can respond to a variety of environmental signals by differentiating into a vigorously swimming flagellate (upper right). This process requires the transcription, translation, and assembly of an entire microtubule cytoskeleton (green), including tubulin. Amoebae also can undergo a closed mitosis (lower left), during which the nuclear envelope remains intact, isolating the spindle microtubules (b/ue) from the cytoplasm. Mitotic microtubules are thought to be built from divergent tubulin isoforms that are expressed prior to mitosis, and then rapidly degraded after cytokinesis 
a useful model for studying centriole assembly, and in fact it was the organism in which de novo centriole assembly was first widely accepted [54]. Naegleria is also well suited for understanding how cells build motile flagella, and transcriptional synchrony of differentiation has been used to identify novel centriole and flagellar components widely conserved among eukaryotes, including humans [74].

Clearly, Naegleria is an organism uniquely positioned to reveal new insights into both crawling and swimming motility. A completely sequenced genome and publicly available transcriptional profiling of differentiation provide first steps toward harnessing this potential [51, 74]. The greatest roadblock remains the lack of usable molecular transformation and gene manipulation techniques, a hurdle we and others are actively attempting to overcome.

\section{$R$ bodies: simple, dynamic protein lattices Jessica K. Polka}

Long-range biological motion is typically the product of nucleotide-dependent motors. For example, actomyosin contraction, the bacterial flagellum, and intracellular transport along microtubules all rely on nucleotidedependent processes carried out by complex assemblies of proteins that can be difficult to reconstitute and engineer. Therefore, if we wish to control biological motion for biotechnological applications (for example, in delivering therapeutic cargoes across membrane barriers), we should instead look for simpler systems.
Some force-generating biological machines are composed of dynamic lattices of proteins that amplify, through polymerization, the nanoscale conformational changes of their protomers to create large scale motion. Unrelated to one another in sequence or structure, these lattices are present in multiple domains of life. They include forisomes (biological "stop-cocks" that can expand to occlude fluid flow in the sieve tubes of plants $[79,80])$, spasmonemes (the motile elements in the stalk of Vorticella that rapidly contract to withdraw the ciliate to its attachment site [81]), and R bodies (coiled structures formed in the cytoplasm of bacteria that extend, when triggered with low $\mathrm{pH}$, to break membranes). Each of these structures undergoes large scale motion without relying on nucleotide hydrolysis. Because $\mathrm{R}$ bodies are large, genetically simple, and chemically robust, they constitute a model system to study the mechanisms of controlled self-assembly and conformational rearrangements that drive functionally related protein machines. Furthermore, they have the potential to act as a powerful chassis for engineering actuators for a variety of biotechnology applications.

In nature, $\mathrm{R}$ bodies are coiled ribbons of protein approximately $500 \mathrm{~nm}$ in diameter that bacteria use to deliver toxins to eukaryotes. Upon exposure to a trigger (such as low $\mathrm{pH}$ ) they rapidly extend in a telescopic fashion to form lancets tens of microns long. This violent extension is driven by protonation, does not require nucleotide fuel sources, and is fully reversible (Fig. 5). Sequences encoding

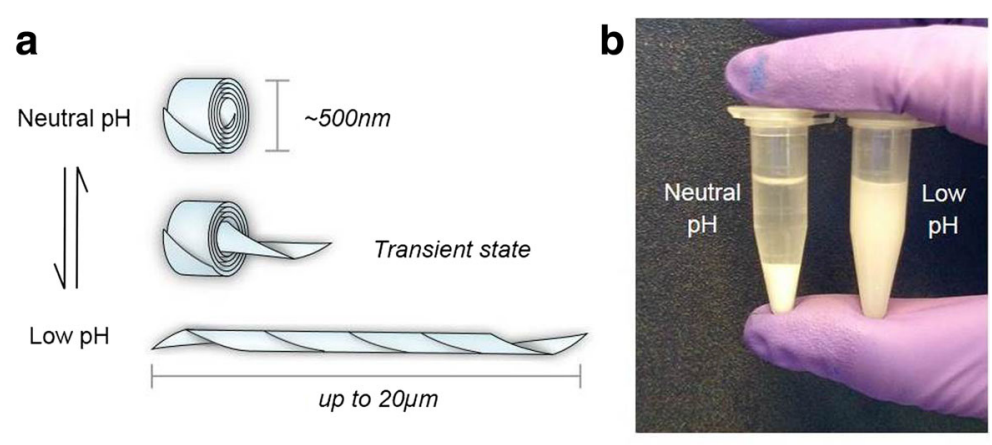

C

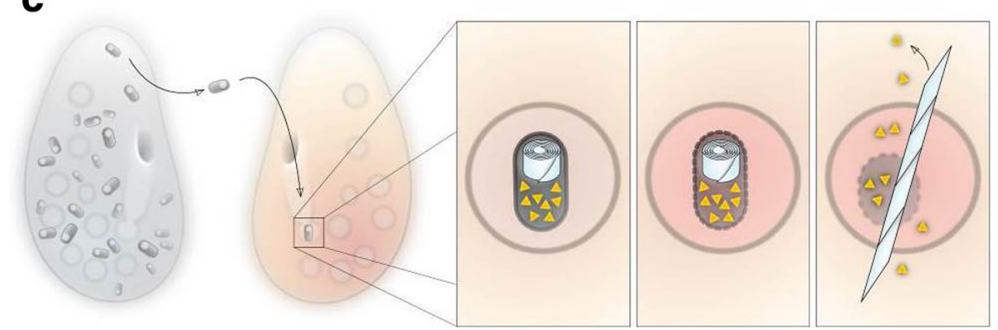

Fig. 5. R-bodies transition between two states. a Type $51 \mathrm{R}$ bodies reversibly transition between a rolled state at neutral pH and a tube state at low $\mathrm{pH}$ by the extension of the ribbon from the center of the coil. The state depicted in the middle is transient. $\mathbf{b}$ This transition is visible macroscopically; coiled $\mathrm{R}$ bodies sediment and extended $\mathrm{R}$ bodies remain in solution. $\mathbf{c}$ When an R-body-containing bacterium is ingested by a sensitive strain of paramecium after being shed by a "killer" strain, the extension of the R body is triggered by the acidic environment of the food vacuole. Extension causes the rupture of the bacterium and the food vacuole, releasing co-expressed toxins that ultimately result in the death of the sensitive paramecium. Images adapted from [89] 
$\mathrm{R}$ bodies are widespread [82], but they were first discovered in Caedibacter taeniospiralis, an obligate bacterial endosymbiont of Paramecium tetraurelia [83, 84]. Strains of the paramecium that carry $C$. taeniospiralis are capable of killing paramecium strains that do not carry the endosymbiont. Bacteria containing the $\mathrm{R}$ bodies are shed into the environment, where they are consumed by sensitive strains of paramecium. In the acidic environment of the paramecium phagosome, the $\mathrm{R}$ bodies extend to puncture the membrane and mix its contents with the cytoplasm (Fig. 5c) [85]. Feeding a diet of purified C. taeniospiralis is lethal to these sensitive strains, but importantly, feeding purified $\mathrm{R}$ bodies is not [86]. This suggests that the $\mathrm{R}$ body itself is not toxic; rather, it acts as a delivery system for a co-expressed toxin.

The mechanisms of $\mathrm{R}$ body assembly and actuation in response to low $\mathrm{pH}$ are largely unknown. Fortunately, $\mathrm{R}$ bodies are extremely simple and eminently tractable: one operon encoding four ORFS (each $<120$ amino acids) is sufficient for their formation in Escherichia coli [87, 88]. By an unknown mechanism, two of these small, nanometerscale polypeptides can self-assemble into an organized structure many orders of magnitude larger than their individual size [87]. This process is representative of a broad biological challenge facing all cells: producing long-range order from components that interact at short length scales. By understanding the assembly processes, we may enable the production of actuators of specified mechanical properties and materials with tunable geometries.

These assembled $\mathrm{R}$ bodies are resistant to sonication, detergents, and diverse buffer conditions, making them stable and robust force-generating machines that could perform work in a variety of micron-scale devices. At the same time, their behavior can be probed with a simple visual assay: under appropriate buffer conditions, contracted $\mathrm{R}$ bodies sediment, while extended $\mathrm{R}$ bodies remain in solution [89]. This change can be easily seen with the naked eye as well as measured quantitatively by absorbance in a plate reader (Fig. $5 b$ ). This assay enables $R$ bodies to be studied in a high-throughput fashion and enabled the identification of mutant $\mathrm{R}$ bodies that can transition at lower or higher $\mathrm{pH}$ than wild type [89].

$\mathrm{R}$ bodies' amenability to engineering suggests that they could be used to deliver biologically active payloads across biological barriers. For example, $\mathrm{R}$ bodies could be conjugated to cargo such as DNA, siRNA, labeled proteins, and other chemicals. This strategy could also be used to transform recalcitrant cell types or to deliver high-value cargoes with improved efficiency.

\section{The awesome power of comparative fission yeast genetics Snezhana Oliferenko}

Working on a "non-model" organism can be exceptionally rewarding because of the promise of new biology, new insights into old problems, and a whole set of new questions to solve. It might be especially tempting to venture to understudied branches of the evolutionary tree to capture the widest possible range of biological diversity. Yet, based on our experience studying mitotic division in two fission yeasts, Schizosaccharomyces pombe and Schizosaccharomyces japonicus, I want to make a case for exploring the cell biology of closely related species. Such a comparative approach is complementary to the development of new "stand-alone" systems discussed elsewhere in this Forum and I would like to argue that it can be particularly powerful if one of the two species is an established model organism.

Eukaryotes have evolved a staggering variety of mitotic mechanisms. Different species and even different cell types within the same organism may take various routes to mitotic spindle assembly [90], nuclear envelope (NE) remodeling [91], and cytokinesis [92]. For example, all dividing eukaryotic cells must remodel the nuclear envelope (NE) to allow chromosome segregation and formation of the daughter nuclei. This invariably involves major rearrangements of the NE-endoplasmic reticulum system coordinated with mitotic spindle dynamics. However, the strategies used to achieve the net result vary from fission of a seemingly intact mother NE into two daughters ("closed" mitosis) to a virtual loss of NE identity in prophase followed by its reassembly around the segregated genomes ("open" mitosis) and several strategies in between [91]. Although work by many groups provided detailed insights into the mechanisms underlying NE remodeling in a number of organisms [93, 94], we understand very little about how these circuitries evolve. Investigating this process in closely related experimentally tractable systems may explain how variation arises in evolution, probe how mitotic nuclear dynamics intersects with the rest of cellular physiology, and inform our understanding of basic NE biology and nuclear origins.

Fission yeasts are a small clade at the base of the Ascomycete phylogenetic tree with overall conservation of gene content and gene structure between the four species [95]. S. japonicus forms an early diverging branch within the clade. Strikingly, S. pombe, a widely used model organism, undergoes closed mitosis but $S$. japonicus breaks the nuclear membrane during anaphase [96, 97] (Fig. 6). We linked this divergence to a simple scaling argument-since nuclei maintain constant volume throughout closed division, cells must increase the nuclear surface area to form two daughter nuclei from one. It turns out that $S$. japonicus does not expand the NE during mitosis, unlike $S$. pombe, and, therefore, must break it to allow chromosome partitioning [96]. Further work showed that divergent regulation of phospholipid biosynthesis in the two yeasts through the phosphatidic 


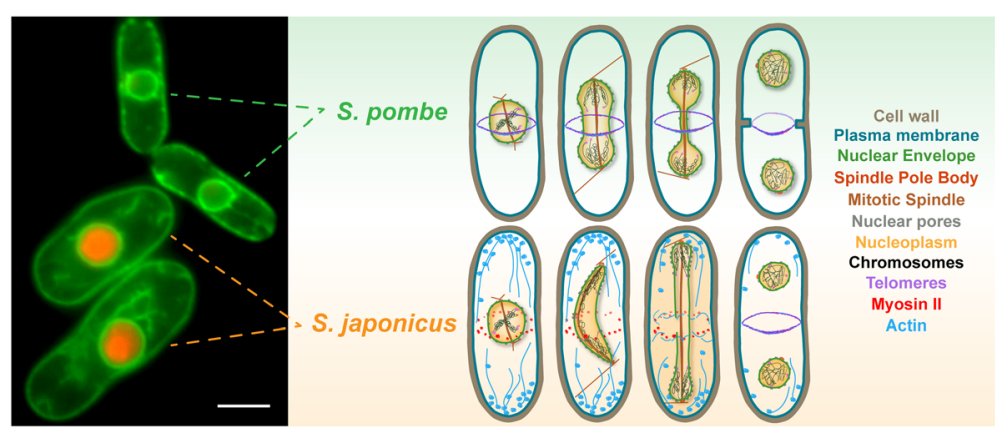

Fig. 6. Schizosaccharomyces japonicus and Schizosaccharomyces pombe exhibit divergent mitotic programs. Left: Live S. pombe and S. japonicus cells expressing the endoplasmic reticulum marker GFP-ADEL and the nucleoplasmic protein Nhp6-mCherry. Note a considerably larger cell size in S. japonicus. Scale bar $5 \mu \mathrm{m}$. Right: Schematic representation of mitotic division in the two sister species. Adapted from [108], Current Opinion in Microbiology, Vol 28, Gu, Y. and Oliferenko, S., Comparative biology of cell division in the fission yeast clade, p.18-25, Copyright (2015), with permission from Elsevier

acid phosphatase Lipin supports the differences in mitotic NE surface area control [98]. These observations may be a starting point in linking the underlying metabolic properties of the cell to the emergence of a particular mode of mitosis.

Another important point of divergence between the two sister species relates to differences in regulating chromatin-NE interactions during mitosis, with unexpected links to nucleolar dynamics. We have shown that although chromosomes must detach from the NE for the duration of mitosis in organisms with closed nuclear division [99, 100], S. japonicus has evolved an anaphasespecific mechanism supporting association between the nuclear pore complexes (NPCs) and chromatin [101]. These interactions executed by the inner nuclear membrane protein of the LEM domain family Man1 ensure equal partitioning of the nuclear membrane and efficient inheritance of the NPCs by the daughter nuclei, which essentially co-partition with segregating chromosomes (Fig. 6). It remains to be seen if variations on this mechanism function in other cell types with relatively early NE reassembly, for example, during karyomere formation in embryonic divisions in some animals $[102,103]$. Yet another LEM domain protein, Lem2, functions in supporting timely NE breakage and reformation in S. japonicus [96]. Thus, this organism can be used as a simple model to elucidate the poorly understood molecular mechanisms responsible for functions of the evolutionarily conserved LEM proteins in maintaining nuclear structure and integrity across eukaryotes [104-106]. Perhaps more surprisingly, in $S$. japonicus chromatin-NE interactions appear to promote disassembly of the nucleolus that takes place in cells where NE integrity is lost during mitosis but not in organisms with closed nuclear division [101].

The examples above illustrate how comparing related organisms may illuminate evolutionary innovations required for attaining specific functions or identify conserved elements obscured by grossly different molecular toolkits of distant species. Knowing one of the model systems well-in our case, S. pombe-allows for an easier transition to a related organism, in terms of both recognizing interesting phenotypes and adapting existing technical tools. Another important advantage of working in closely related systems is the relative ease of pinpointing the divergent nodes in otherwise conserved networks supporting cell biological processes, and retroengineering the processes with novel properties in the sister species. We have been using the latter approach in our studies of mitotic NE dynamics but also to investigate division plane positioning in the two yeasts. Cells of both species divide in the middle but our studies suggest that $S$. pombe, a popular model for cytokinesis research, has evolved an unusual medial division ring assembly mechanism based on neofunctionalization of one of the recently duplicated anillin paralogs [107]. Importantly, unlike S. pombe that assembles the actomyosin ring in metaphase and requires a mechanism preventing its precocious constriction, S. japonicus initiates ring assembly only at mitotic exit, similarly to animal cells [107, 108] (Fig. 6). In general, the metazoan-like properties of S. japonicus division ring assembly combined with mitotic NE breakdown make it an attractive new model for studying regulation and mechanisms of cytokinesis [109].

The salient differences in cell biology between the two species outlined above are likely just the tip of the iceberg. S. japonicus can be used as a valuable system on its own to study phenomena not apparent in the established yeast models. Importantly, it has all the advantages of the simple experimental system, including straightforward culturing, short cell cycle, and the ease of genetic manipulations-the latter owing largely to Hironori Niki whose group developed $S$. japonicus 
genetic tools [110, 111] and Nick Rhind who spearheaded the fission yeast clade genomes project. Beyond its utility studying mitotic NE dynamics and other aspects of mitotic division, S. japonicus could become a great system for investigating the cell biology of hyphal transition [112, 113], energy metabolism [114], and centromere biology $[95,115]$. Yet, it is capitalizing on the "experiment of Nature" and using the two sister species alongside each other that offers conceptually new possibilities in cell biology by expanding its evolutionary dimension.

\section{Ashbya gossypii as a model for cytoplasm organization}

\section{Therese Gerbich and Amy Gladfelter}

All cells face challenges in spatial organization of their contents. One solution used by eukaryotic cells is to create individual membrane-bound compartments for specialized cellular functions. But cells also need to be able to organize all the cytosolic spaces between these compartments so that biochemistry, signaling, and protein production can be tightly regulated. Gradients are one example of organization that is widely observed from micron-sized bacteria to developing insect embryos [116, 117]. How cytosolic patterns are established and maintained in spite of the dissipative power of diffusion is an area of active investigation in a variety of systems. However, the problem is especially striking in syncytial cells where many nuclei are enclosed in a large, single cytoplasm. Syncytia are found in diverse contexts, including human muscle and placental cells, many fungi, developing insects, and plant tissues. These special cell types face even greater challenges in organizing their cytosolic contents, making them a powerful place to study fundamental principles of cytoplasmic organization.

A non-traditional syncytial model system that has been enormously useful for uncovering principles of cytosolic organization is the filamentous fungus Ashbya gossypii (Ashbya)(Fig. 7, left). Ashbya is an ascomycete that is closely related to Saccharomyces cerevisiae, but with a rather different lifestyle [118-120]. It has a small genome with 4000 genes, tolerates replicating plasmids, is readily transformed, and is amenable to molecular genetics via gene targeting [121-123]. It has been a valuable system for understanding highly polarized growth and nuclear movement, and is even used as an industrial producer of riboflavin. What makes the system notable for cytoplasmic organization studies is that the many nuclei in the continuous cytoplasm go through the nuclear division cycle asynchronously [124]. This is remarkable because one would expect that all nuclei would go through the cell cycle together, as global levels of each cyclin protein rise and fall in the common cytoplasm. In studying this paradoxical cell cycle, new modes of cytosolic organization have been revealed.

Ashbya nuclei create local zones within the cytoplasm to insulate neighboring nuclei from one another so that their division cycles don't entrain. One way these territories of cytosol form is through an RNA-binding protein that self-associates and positions mRNA transcripts of a G1 cyclin near nuclei [125] (Fig. 7, middle and left). The protein contains a large polyQ tract that enables it to form phase-transitioned assemblies that then trap cyclin transcripts in the vicinity of nuclei. If this protein can no longer undergo a phase transition and position cyclin transcripts, nuclei in the shared cytoplasm divide more synchronously $[125,126]$. While the ability of proteins to undergo liquid phase transitions in vivo and in vitro had been observed previously, studies in Ashbya are one of the best connections of a biological function (positioning of cyclin transcripts to establish and maintain nuclear asynchrony) to regulated protein phase transition.

Cytosolic compartments are not just important for nuclear cycling in Ashbya but also in cell polarity. Ashbya

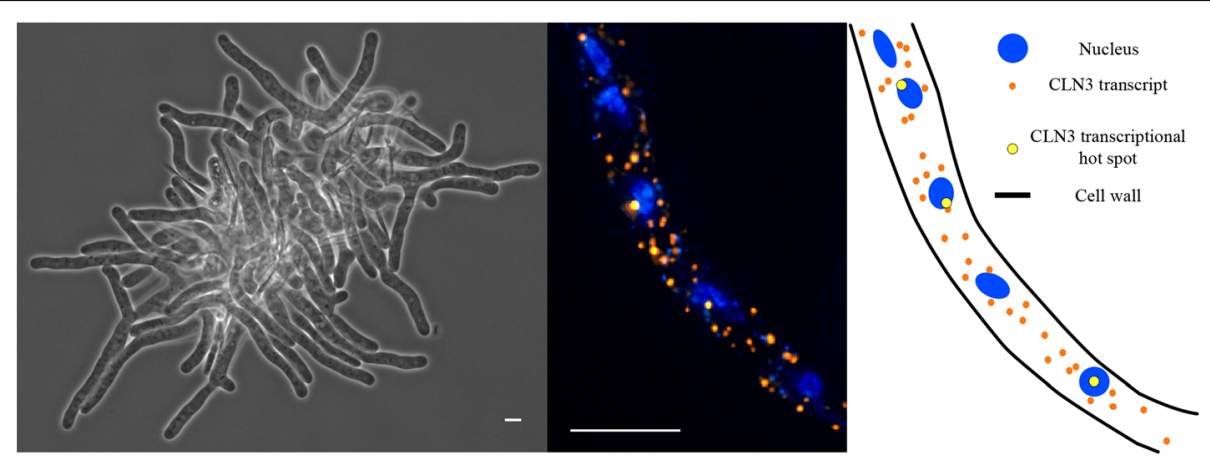

Fig. 7. Ashbya gossypii as a model for cytosolic organization. Left: image of a growing young mycelium. Middle: A.gossypii hyphae with clustered mRNA transcripts. Asynchronously cycling nuclei are shown in blue and clustered cyclin transcripts in orange. Right: cartoon depiction of A.gossypii hyphae with nuclei and clustered transcripts. Scale bars $5 \mu \mathrm{m}$ 
grows exclusively in a polarized manner at cell tips such that many polarity axes coexist in a shared cytoplasm and new growth sites have to be established throughout the cell. The same RNA-binding protein that acts near nuclei forms physically distinct liquid compartments at incipient and established growth sites. These liquid droplets are important for positioning RNAs involved in polarized growth and potentially locally regulating their translation [127]. Future work in this organism will be important for understanding how different liquid compartments form, coexist, and function within a shared cytoplasm. By taking advantage of the special features that the biology of these cells offer, study of Ashbya can identify mechanisms of cytoplasmic organization relevant to all eukaryotes. A key lesson from this and all unconventional systems is that it is important to embrace biological paradoxes and try to figure them out. We have only just begun to tap into understanding the diverse ways cells and tissues solve the problems of staying alive.

\section{Volvox: revealing the origins of multicellularity and germ-soma division of labor \\ James Umen}

Multicellularity evolving from unicellular ancestors is considered one of the major evolutionary transitions [128], with at least two dozen independent occurrences among five major eukaryotic super-clades [129-131]. Approaches aimed at understanding the origins of multicellularity, particularly for plants (embryophytes) and animals (metazoans), are challenged by the difficulties associated with reconstructing ancient events based on deeply divergent extant multicellular and unicellular lineages. Volvox and its close relatives (the volvocine green algae) are an alternative model for investigating multicellularity, including the early origins of traits such as cell adhesion and intercellular connections, cell-type differentiation with dedicated germ cells and terminally differentiated somatic cells, asymmetric cell divisions, morphogenetic patterning, and sexual dimorphism-all of which are found in more complex multicellular taxa. What differentiates volvocine algae from other taxa and makes them a unique model is their simplicity and their relatively recent transition to multicellularity, with several well-characterized genera that capture successive increases in morphological complexity [132, 133] (Fig. 8a). Conveniently, a close relative of all multicellular volvocine algae is the well-studied unicellular model organism Chlamydomonas reinhardtii (Chlamydomonas) [134, 135] that serves as an outgroup and a proxy for the ancestral state of the lineage.

Volvox carteri (Volvox) has been used as a "nonmainstream" model for development for several decades [136, 137], and belongs to a genus with a distinguished history that dates back to some of the earliest recorded light microscopic observations that were made by van Leeuwenhoek [138]. Vegetatively propagated Volvox individuals have a spheroidal shape and exhibit a streamlined body plan composed of just two cell types: 2000 small terminally differentiated somatic cells arranged on the spheroid exterior with flagella oriented outward to provide motility, and $~ 16$ large reproductive cells called gonidia located on the interior (Fig. 8b-e). All cells are embedded within an extensive clear extracellular matrix that occupies $\sim 99 \%$ of the spheroid volume. Volvox somatic cells are similar in size and overall structure to Chlamydomonas cells (Fig. 8f), though they possess several unique derived features that distinguish them from Chlamydomonas cells in form and function [139] (Fig. 8a).

The appeal of Volvox as a model for investigating the evolutionary and mechanistic bases of multicellularity derives not just from the potential to build on several decades of detailed developmental and genetic studies but also from increasing information on related genera whose genome sequences are enabling the history of developmental innovations and their genetic origins to be reconstructed [140-142]. Intriguingly, all of the developmental regulators identified so far in Volvox (as yet only a handful) have either Chlamydomonas orthologs or are members of protein families whose origins can be traced to related families in Chlamydomonas [132]. In some cases orthologs are interchangeable between the two species, raising unanticipated questions about ancestral gene function when the trait governed by the Volvox gene has no obvious parallel in Chlamydomonas (for example, tissue morphogenesis or asymmetric cell division [143]).

As with any experimental system, the questions one can ask are dictated by available tools and resources, some of which have been reviewed recently [135]. The focus here is on Volvox, but it should be understood that Chlamydomonas has available an even more extensive molecular genetic toolkit, making it an ideal partner species for integrated and comparative cellular, developmental, and evolutionary studies. Three volvocine genomes are now published and publicly accessible-those of Volvox carteri, Chlamydomonas reinhardtii, and Gonium pectorale [140-142]. All three haploid genomes are similar in size (120-150 Mb) and have roughly similar gene contents with an extensive degree of 1:1:1 protein-coding-gene orthology. Several more genome sequences from species belonging to other volvocine clades are forthcoming. All volvocine algae can be propagated vegetatively (that is, mitotically) as diagrammed in Fig. 8g for Volvox, but also have facultative, inducible sexual cycles that allow mutants to be isolated and subjected to classic genetic analyses [144, 145]. Transposon tagging was developed to bypass the need for crossing 


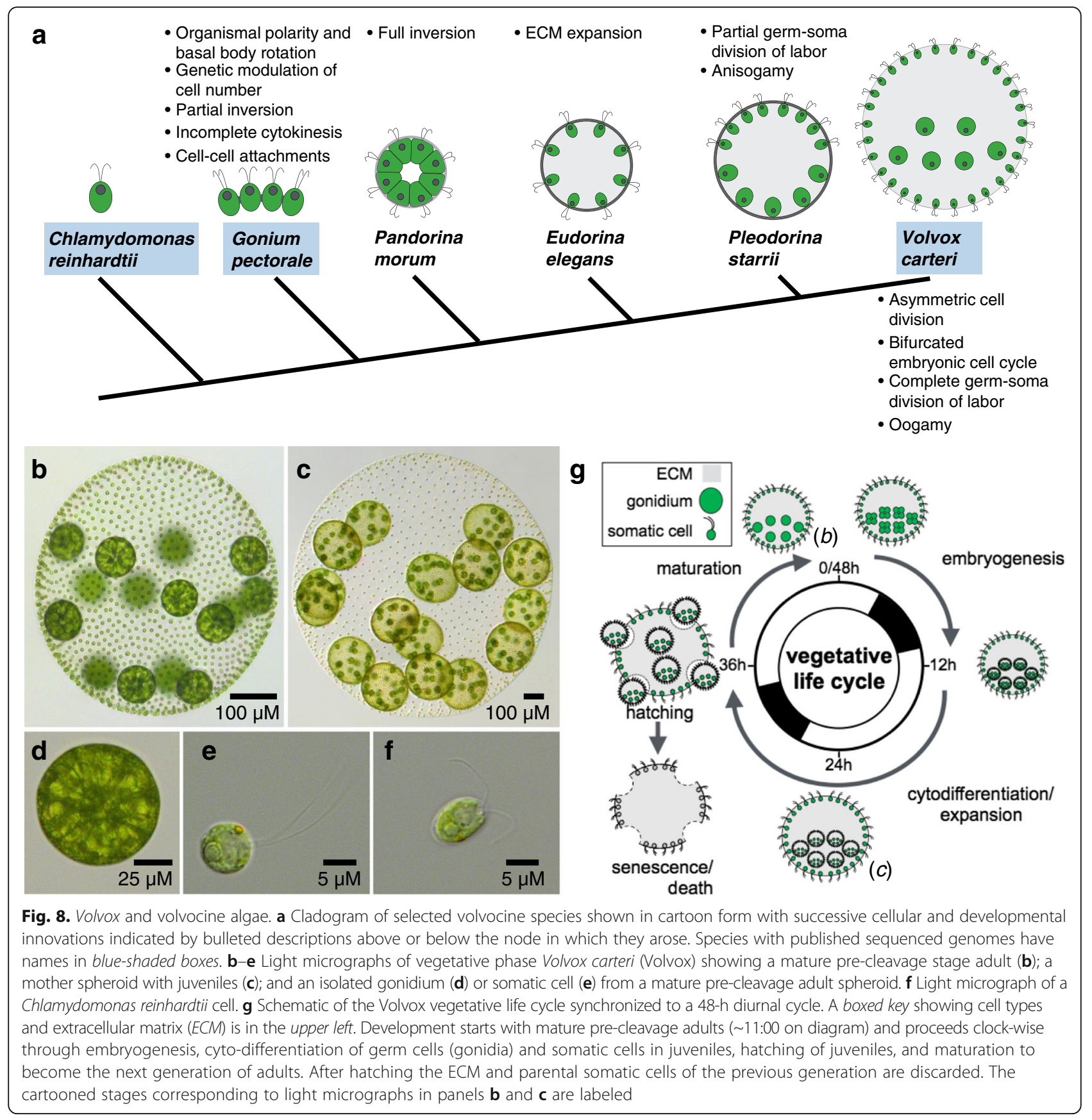

which can be tricky [146-148], but there are newer isolates of Volvox that perform well in crosses [149], and in my opinion classic genetic approaches such as UV or chemical mutagenesis followed by screening, outcrossing, and whole genome re-sequencing will be the preferred way to characterize and identify mutants going forward. Volvox is transformable with exogenous DNA that integrates randomly into its haploid genome, and a variety of transgenes have been expressed including fluorescently tagged proteins, antibiotic resistance markers, and endogenous genes [150-154].
Hairpin and antisense-based gene expression knockdowns can also be done, making reverse genetics feasible $[149,155,156]$. While CRISPR-Cas9 editing has not been reported yet for Volvox, it has been successful in Chlamydomonas and could be developed for other volvocine species [157, 158].

As a developmental system Volvox has some appealing features, including organismal size and clarity that make it well suited to live-cell 3D imaging methods, including selective plane illumination microscopy (SPIM) [159]. The chlorophyll and other 
pigments that are in Volvox cells can interfere with live-cell fluorescence detection methods just as in plants, but more discriminating confocal microscopy technology and sensitive detection systems have helped to mitigate this issue [160]. Vegetative Volvox is easy to mass culture and will synchronize under a two-day diurnal cycle (Fig. 8g). In addition, the individual spheroids are large enough that rapid visual screens for developmental mutants can be performed using only a dissecting microscope and micropipette to pick out candidate mutants. Embryonic cleavage follows a stereotyped pattern, and the lineage relationships between cells during normal development are known; but interestingly, cellsize is the ultimate determinant of germ-soma differentiation for post-embryonic cells [161]. Many fascinating and potentially valuable developmental mutants of Volvox that affect specific multicellular and developmental traits have been described [137], and some causative genes have been identified [132], but most mutants are no longer in culture (as yet there is not a routine way to freeze Volvox cultures, though there has been some success reported [162]).

The pieces are in place to implement a promising approach for investigating multicellular innovations and their origins in Volvox using a combination of forward and reverse genetics, and making use of Chlamydomonas and other volvocine species to interrogate ancestral gene functions and origins. Descriptions of previously isolated mutants, including several that alter germ and somatic cell fates, provide an indication of the untapped riches of Volvox development [132], and with a sequenced genome and relatively inexpensive sequencing technology it is now possible to go from mutant phenotype to causative mutation in a matter of weeks. Once a mutant is identified and verified, its function can be studied not only in Volvox, but also in Chlamydomonas and other volvocine species where the causative gene is likely to have a 1:1 ortholog (or at least a homolog). In some cases Volvox and Chlamydomonas orthologs will be interchangeable in function, and in other cases not; but either result can be informative for understanding the relationships between ancestral and derived traits in the volvocine lineage. A similar combined comparative genomics and experimental approach for investigating evolutionary divergence of mitotic mechanisms in fission yeasts is described by Snezhana Oliferenko elsewhere in this Forum.

The approach outlined above is only one of several productive ways in which Volvox can be used to ask about the origins of multicellular trait innovations, and is meant to stimulate thinking about the new possibilities that genomics and other recent technologies add to this model system. Most importantly, the opportunities for exciting discoveries far outnumber the researchers who are currently using Volvox and its relatives. A great way to learn more about Volvox and volvocine algae and to tap into this research community is to attend a meeting [163, 164], or to visit a laboratory that uses these intriguing microcosms of multicellularity and experience first-hand their beauty and the scientific wonder they inspire.

\section{Physcomitrella patens: harnessing anatomical simplicity to investigate the cellular basis of tissue morphology Magdalena Bezanilla}

Living organisms use their genome as a blue print to build intricately complex and beautiful structures. Within an organism, where every cell has the same blue print, simply controlling how the blueprint is read leads to the formation of different body parts. However, even single cells establish and maintain unique shapes, evidenced by the vast morphological diversity amongst unicellular organisms. In many organisms, cell shape stems from restrictions imposed by the extracellular environment. Eukaryotes control this by building a wide variety of extracellular structures. For example, animals build bones and shells, plants build polysaccharide walls, and diatoms construct silica-based frustules as described in this Forum by Russell and Theriot. Extracellular structures, which often are patterned over macroscopic scales, impose constraints on both cellular and tissue morphology. Yet, individual cells are responsible for depositing extracellular matrix. Thus, how organisms control this large-scale patterning of their extracellular matrices is an open question.

To gain insight into this question, it would be ideal to work on an organism whose body plan enables imaging of individual cells within tissues, and that builds a complex extracellular matrix in the context of a variety of tissues throughout development. Although land plants, with their polysaccharide walls and their indeterminate growth, certainly satisfy the latter criterion, access to individual cells within all tissues is challenging in the vast majority of vascular plants. In contrast, the moss Physcomitrella patens (Physcomitrella) satisfies both criteria. The Physcomitrella body plan is simple, with most tissues only a single cell layer thick, thereby providing an excellent system with which to dissect intracellular control in patterning of the extracellular matrix.

Physcomitrella germinates from a haploid spore, producing a linear array of cells that branch out leading to a filamentous network known as protonemata (Fig. 9). The initial cells that germinate from the spore and establish the network are chloronemal cells (Fig. 9). In protonemata, the apical cell is the stem cell, dividing leaving a subapical cell and a new apical stem cell. The filamentous network is further elaborated by branching 

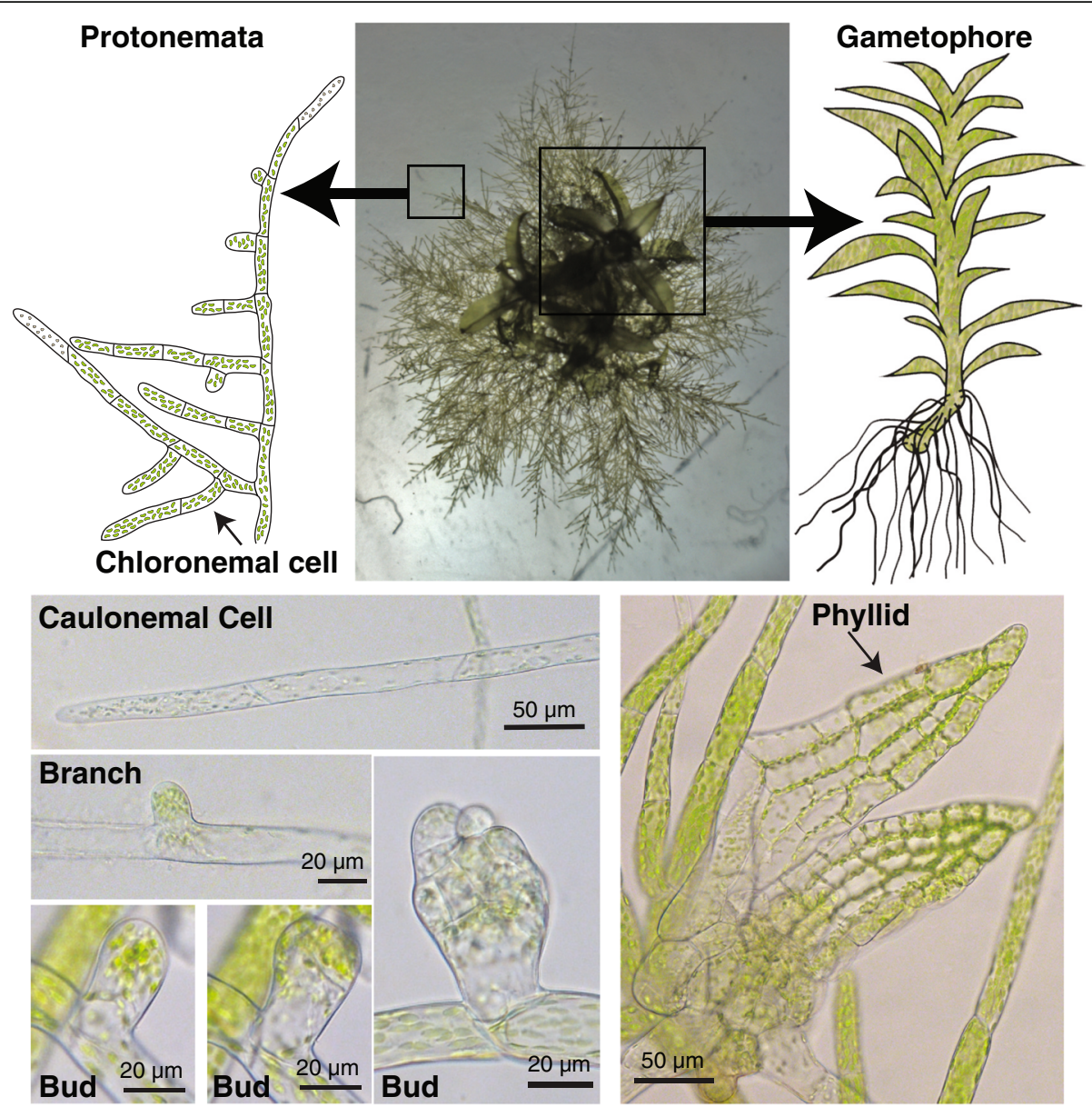

Fig. 9. Haploid tissues of the moss Physcomitrella patens. A plant regenerated from protoplasts is shown in the top center. The boxed regions in this image represent the juvenile (protonemata) and adult (gametophore) tissues, which are drawn schematically on either side of the image. Images acquired from tissue grown in microfluidic devices showing a variety of cell types and tissues are shown in the bottom row

events, whereby a subapical cell undergoes an asymmetric division generating a new apical stem cell that gives rise to a daughter filament. As the plant matures, the apical cells differentiate into a second cell type known as caulonemal cells (Fig. 9), which are characterized by faster growth and obliquely positioned cell plates. Caulonemal cells are developmentally distinct as they can grow in the absence of light whereas chloronemal cells cannot [165].

The filamentous network is the juvenile state of the plant and establishes a radial symmetry (Fig. 9). This network begins to mature into the adult plant by undergoing an additional developmental transition characterized by the emergence of buds (Fig. 9) from subapical cells. Buds represent a switch from two- to threedimensional growth. The bud initially resembles a new branch but the apex of the cell is more rounded and the first division is oblique (Fig. 9), establishing the apical basal axis. Both daughter cells divide perpendicularly to the first oblique division [166]. This division generates the apical stem cell in the bud. The bud eventually develops into gametophores that have leaf-like structures known as phyllids (Fig. 9). Phyllids emerge regularly off the gametophore and are only a single cell layer thick.

Within the vegetative state of Physcomitrella, both juvenile and adult tissues are a single cell layer thick and thus readily accessible to microscopic observation. Furthermore, these tissues grow via distinct mechanisms. The juvenile state grows two-dimensionally by polarized secretion of extensible cell wall material to the tip of the apical stem cell, enabling turgor-driven cell expansion only at the cell apex. In contrast, the adult state switches to three-dimensional growth characterized by diffuse cell expansion. Strikingly, the gametophore is generated from a single apical stem cell [166], a dramatic simplification in comparison to seed plants, which have an apical domain known as the meristem comprised of several layers of undifferentiated stem cells. 
Even with the relatively simple anatomy of Physcomitrella, continuous imaging over developmental time of events that occur in the denser regions of the filamentous network, such as caulonemal cell maturation and bud formation, has been challenging. Phyllid expansion that occurs in the air and in three dimensions was also not accessible to high-resolution imaging. Recently these limitations have been largely overcome by the ability to grow Physcomitrella in custom-made microfluidic imaging chambers for weeks [167], providing the unique opportunity to observe protonemal tissue differentiation, bud formation, and phyllid expansion at cellular and subcellular resolutions.

Another feature that makes Physcomitrella a particularly useful model system is the ability to propagate the plant vegetatively. Upon mechanical disruption, cells in the damaged tissue de-differentiate into chloronemal cells, re-establishing a new plant. This effectively enables indefinite propagation of any Physcomitrella line, which is especially useful for mutant strains with developmental defects. As an extreme example of vegetative propagation, it is possible to remove the cell wall from Physcomitrella tissue enzymatically, generating a suspension of protoplasts, which given appropriate osmotic conditions then rebuild their walls and generate a new plant resembling one germinated from spores.

Protoplasts are also easily transformable with DNA [168] opening the door to genetic manipulations. Among these is the ability to use homologous recombination for gene targeting [169-171], a feature unique to mosses amongst land plants, which has made it possible to generate lines that express native proteins fused to reporter genes [172] or fluorescent proteins expressed from their own genomic context [173]. Most recently CRISPR-Cas9-mediated gene targeting has also been shown to generate genomic lesions effectively $[174,175]$. Because juvenile and adult tissues are haploid, a genomic lesion immediately results in a mutant. Additionally, RNA interference (RNAi), which can target multiple genes simultaneously, can be performed transiently $[176,177]$ or inducibly [178], enabling lossof-function studies of whole gene families. Finally, since whole-genome sequencing has become routine, it is also possible to identify genomic lesions introduced by random mutagenesis [179].

The extensive genetic tool box coupled with facile imaging of single cells within the context of whole tissues uniquely positions Physcomitrella among land plants as an excellent model organism. In addition to interrogating how molecules within individual cells pattern extracellular matrix over macroscopic length scales, Physcomitrella provides the opportunity to answer key questions in plant cell and developmental biology.

\section{Cerebral organoids model human brain development and disease Madeline A. Lancaster}

For centuries, the human brain has been one of the most difficult organs to study. The brain is what makes us unique, both as individuals and as a species. But for this very reason, its particular features are impossible to study in other organisms, and ethical and methodological limitations prevent us from directly studying it mechanistically. So while animal models have provided insight into what it is to be a vertebrate, a mammal, or even a primate, there still remain many questions surrounding what it is to be human. For example, while neural stem cells behave in much the same fashion in all vertebrates, their neurogenic potential is greatly increased in humans, giving rise to over a thousand times the number of neurons in a mouse brain [180], and a brain that is over three times larger than our closest relatives, chimpanzees and bonobos [181]. Furthermore, there are important differences in cytoarchitectonic organization, such as the presence of grey matter minicolumns [181] and numerous unique interneuron populations in the cortex [182, 183], and overall denser, more complex dendritic trees and spines [184].

Because of these unique features, it has proven difficult to recapitulate many human neurological disorders accurately in mouse models. For example, primary microcephaly (small head size) in humans is caused by homozygous null mutations in any of a number of centrosomal or DNA repair genes, yet when these mutations have been introduced in mice, the effect on brain size is minimal [185]. Likewise, mouse models of human mutations seen in neurodegenerative conditions fail to display the full range of defects, such as both plaques and tangles seen in brains of patients with Alzheimer's disease [186]. These are just a couple of the numerous failures to model human neurological conditions in traditional animal models, which unfortunately has led to a drying up of the drug pipeline in this area, and a lack of further interest on the part of the pharmaceutical industry [187].

Recently, neuroscientists have turned their attention in vitro with the hope that human features might be modeled using human neural cells. However, until very recently, in vitro meant a disorganized layer of cells grown in 2D, hardly capable of being considered a model of any developing organ. Then, in 2001, Zhang et al. established the first so-called neural rosettes [188], which modeled with remarkable fidelity the epithelial arrangement of neural stem cells and the formation of neural tube-like lumens. Over the next 10 years, improvements were made in the reproducibility and efficiency of formation of neural rosettes [189, 190], and in 2008, Eiraku et al. published the SFEBq method [191] 
for generation of larger, more complex rosettes as a result of culturing in $3 \mathrm{D}$ before plating tissues in $2 \mathrm{D}$. Building upon these studies, in 2013, we developed a completely 3D model system of human brain development: so-called cerebral organoids [192]. Because of their reliance on endogenous signals, cerebral organoids are capable of remarkable self-organization resulting in complex tissues containing a variety of interconnected brain regions. That same year, Kadoshima et al. established a 3D method for generation of forebrain tissues [193], and in 2015, Paşca et al. developed a method for generating spheroids containing cortical rosettes [194].

Overall, the methods that have arisen in the past 5 years have revealed the remarkable ability of stem cells to self-organize and form tissues reminiscent of the early developing brain. While cerebral organoids contain a variety of brain regions with remarkable complexity, spheroids generated with exogenous patterning factors and small molecules more reproducibly generate forebrain and cortical rosettes [195]. But one thing all the methods have in common is the ability to accurately model the behavior of neural stem cells and their organization into discrete progenitor zones highly reminiscent of the tissue architecture in vivo. Because of their organization, species-specific differences in tissue architecture and stem cell behavior can be detected in neural organoids (Fig. 10). For example, human cerebral organoids display large numbers of outer radial glia $[192,193]$, an extra population of neural stem cells that is highly abundant in the developing primate brain, but limited in mice. Furthermore, differences in both neural stem cell division dynamics and fate have recently been described between human and non-human primate organoids [196, 197].

The fact that brain organoids display human-specific features holds great promise for their use in modeling neurological disorders. Indeed, despite their very recent development, neural organoids have already been demonstrated to model features of microcephaly [192], autism [198], lissencephaly [199], and even Zika virus infection [200, 201]. A further testament to their utility is the increasing adoption of these methods in numerous independent laboratories. As with many novel technologies, widespread adoption takes time and so from the cerebral organoid paper in 2013 through 2015 only four publications made use of 3D neural organoids. But last year alone this number jumped to 19 and there is no sign of slowing in the immediate future. While it is still early days, the hope is that the application of brain organoid methodologies to the study of an increasing number of neurological syndromes will provide a treasure trove of new insight into disorders of this previously enigmatic organ.

\section{Nematostella vectensis: born to be a starlet}

\section{Shuonan $\mathrm{He}$ and Matthew C. Gibson}

Cnidarians have long attracted attention from biologists and it is easy to see why. From Abraham Trembley's classic illustrations of regenerating hydra to Ernst Haeckel's vivid depiction of discomedusae and sea anemones in Art Forms in Nature, these delicate creatures exhibit an exotic beauty [202, 203]. For contemporary

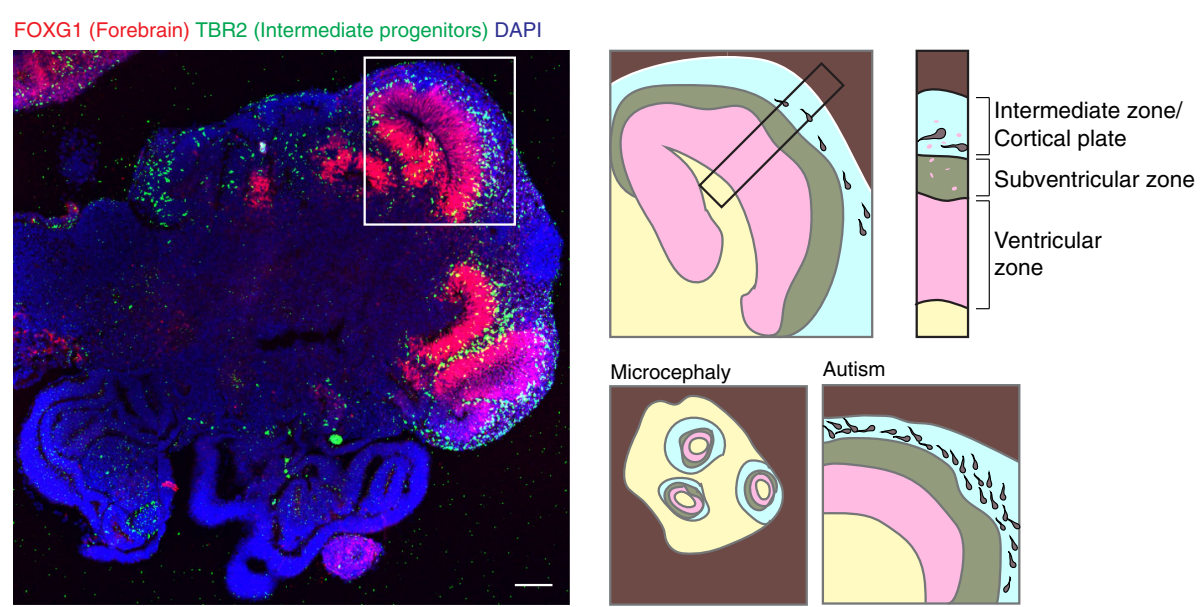

Fig. 10. Cerebral organoids model the architecture of the developing human brain. Left: a section of an entire cerebral organoid stained for the forebrain marker Foxg1, the intermediate progenitor marker Tbr2, and DAPI, revealing the presence of lobules of cerebral cortex as well as other brain regions not positive for Foxg1. Right: a schematic of a lobule of cortex in an organoid showing the proper organization of progenitor zones: ventricular zone (VZ) where radial glial neural stem cells reside, subventricular zone (SVZ) where transit amplifying populations reside, and the intermediate zone (IZ) and cortical plate (CP) where neurons migrate to their final positions. Scattered pink puncta represent outer radial glia, a population abundant in human brain development but much less present in rodents, while elongated purple neurons represent tangentially migrating interneurons that originate outside the cortex. In the case of microcephaly (lower left) organoids overall are much smaller, as are progenitor zones [192], whereas organoids derived from autistic patients display increased numbers of interneurons [198]. Scale bar $100 \mu \mathrm{m}$ 
studies of evolutionary cell and developmental biology, cnidarians have begun to offer much more than simple visual appeal. Widely accepted as the sister group to bilaterian animals, cnidarians possess apparent radial symmetry, lack definitive mesoderm, and have only a single opening that functions as both mouth and anus [204, 205] (Fig. 11). Beyond aesthetic intrigue, these morphological distinctions indicate key evolutionary transitions in the bilaterian lineage after the split of both phyla from their common ancestor, making cnidarian biology central to our understanding of animal evolution. Nevertheless, more than 250 years after Trembley's pioneering work, we still know surprisingly little about the molecular mechanisms that dictate the distinguishing morphological features of cnidarians. One major obstacle has been the absence of a singular cnidarian species that is equally tractable for developmental, cellular, and genomic analysis.

Addressing this issue, the starlet sea anemone Nematostella venctensis (Nematostella) has emerged at the forefront of cnidarian model systems with the potential to serve broad research interests.

Nematostella is an estuarine, burrowing sea anemone, first described and named by Thomas Stephenson in 1935 [206]. In the wild, they can be found in brackish ponds or marshes along the coast with recorded salinities ranging from 8.96 to $51.54 \%$ and water temperatures from -1 to $28{ }^{\circ} \mathrm{C}$ [207, 208]. Adaptation to such an ever-changing habitat might explain why Nematostella is exceptionally easy to culture in the laboratory compared with most other cnidarian species. Nematostella belongs to the class Anthozoa, which consists of corals, sea anemones, and sea pens. Phylogenic analysis based on morphology, rRNA, 18S rDNA, and mtDNA data placed Anthozoa at a more basal position within the cnidarian phylum [204, 209-212]. Indeed, it has been proposed that the Anthozoan life history (with only a sessile polypoid adult form) represents the ancestral state of cnidarians [213-215]. If the polyp-first hypothesis is correct, comparative studies using Nematostella are ideal for reconstructing morphological traits of the putative bilateria-cnidaria common ancestor.

Nematostella is a dioecious species. Although sexual plasticity has been reported in other Anthozoans, this phenomenon has not been observed in Nematostella $[216,217]$. In the lab, spawning can be induced easily by subjecting sexually mature animals to a combination of light and heat shock [208, 218, 219]. During spawning, females produce gelatinous egg masses, each containing hundreds of eggs, while males release sperm directly into the water. This highly controllable spawning process enables access to large quantities of synchronized developing embryos that are amenable for further experimental manipulations. Nematostella has a simple Anthozoan life history with no medusa stage. The fertilized egg undergoes a series of "chaotic" cleavages, and quickly forms a

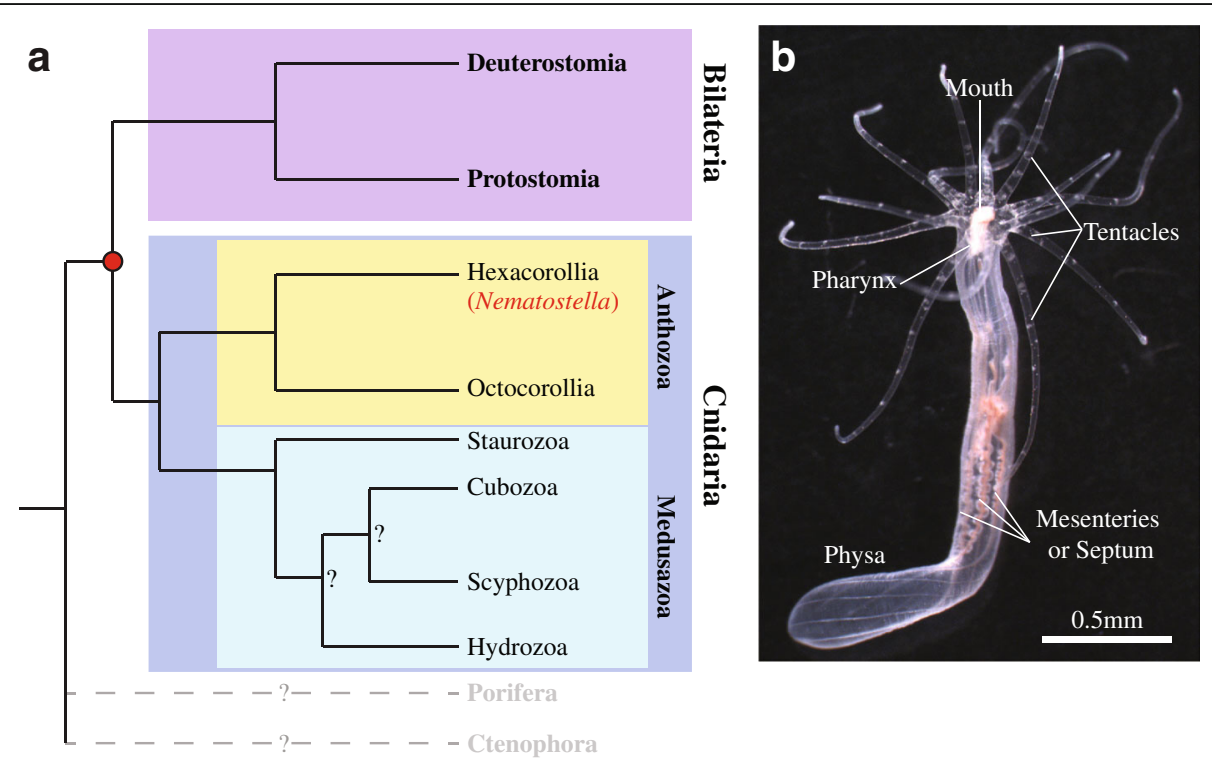

Fig. 11. Nematostella vectensis phylogenetic position and juvenile morphology. a Metazoan phylogenic tree highlighting the position of Nematostella. The detailed ingroup relationships of medusozoa, as well as the position of Ctenophora and Porifera, are still uncertain, as indicated by question marks. b Morphology of a fully relaxed juvenile Nematostella vectensis polyp. The thickened internal foldings along the body column are called mesenteries. These delicate structures contain digestive glands, and retractor muscles as well as gonads. The reddish coloration of mesenteries is due to feeding of Artemia nauplii under laboratory conditions. Tree in a adapted from [209, 326, 327]: Bridge, D; Cunningham, C W, Class-level relationships in the phylum Cnidaria: molecular and morphological evidence, Molecular Biology and Evolution, 1995, Volume 12, Issue 4, p.679-89, by permission of Oxford University Press and Society for Molecular Biology and Evolution 
well-organized single epithelial layer. Epithelial polarity is established in early cleavage stages, providing a perfect system to study epithelial formation, growth, and morphogenesis during early embryogenesis. Embryos gastrulate around 20 hours post fertilization, developing only two germ layers, the ectoderm and the endoderm (also referred to as the entoderm or endomesoderm). Within 48 hours post-fertilization, the embryo develops into a fully ciliated, free-swimming planula larva and starts to escape from its surrounding gelatin matrix. By day seven, elongated planulae settle down and metamorphose into polyps bearing four tentacles [220, 221]. Under optimal conditions, it takes 2 to 3 months for a juvenile polyp to reach sexual maturity. Once sexually mature, spawning can be induced every 2 to 3 weeks year round without damaging the animals. Nematostella can also undergo asexual reproduction, which usually occurs via transverse fission through the body column, and can be triggered by extensive feeding, even prior to sexual maturation [222]. Interestingly, the life span of Nematostella remains undetermined as it apparently exceeds the "life span" of a PhD student or postdoc.

Nematostella was the first cnidarian to have its whole genome sequenced. The high-quality genome sequence revealed the presence of the majority of the gene repertoire for bilateria development and biochemical processes in the eumetazoan ancestor [223]. More strikingly, at the genomic level, vertebrates share more similarities with Nematostella than with ecdysozoans (including, for example, fruit flies and nematodes) [223-226]. Despite the notable conservation of intragenic sequence and gene structures, the conservation of function as well as regulation of these genes remain poorly explored. Fortunately, a rapidly expanding Nematostella toolkit will fulfill this purpose. Morpholino and mRNA delivery via microinjection has proven to be a powerful approach to manipulate gene expression level [227]. Meganuclease-mediated transgenesis is also well established, which helped the generation of several tissue- and cell lineage-specific reporter lines [228-230]. Genomic approaches such as ChIP-seq enable the identification of potential enhancer/promoter regions for certain genes and allow a careful dissection of the gene regulatory network [231]. Most importantly, to our knowledge, Nematostella is the only cnidarian system where TALEN- and CRISPR/Cas9-mediated genome editing has been reported $[232,233]$. The ability to generate knockout as well as knock-in mutants opens up new possibilities and finally permits sophisticated genetic analysis of gene functions in a cnidarian species.

Over the past decade, studies on Nematostella have shed light on a few fundamental innovations of bilaterian evolution, including the determination of body axis [233-236], the origin of mesoderm [237, 238], and the emergence of a centralized nervous system $[229,230,239,240]$. Through these studies, a surprising new picture is emerging of a morphologically and genomically complex eumetaozoan ancestor. Paralleled by progress in other cnidarian model systems [241-244], future research using Nematostella will provide new insights into common molecular mechanisms behind the diversity of life and promises to reshape our understanding of animal evolution.

\section{Water bears: evolution of body forms and survival of extremes}

\section{Bob Goldstein}

In May 1997, a new molecular phylogeny of the animals revealed that $C$. elegans and Drosophila were much more closely related than had been thought [245]. Previous phylogenies had placed the nematodes (which include C. elegans) and arthropods (which include Drosophila) so distantly from each other that arthropods were thought to be even more closely related to us than they were to nematodes. But the new work revealed that these two groups were united along with a handful of hard-to-pronounce animal phyla: onychophorans, kinorhynchs, priapulids, nematomorphs, tardigrades, and later the loriciferans as well. I thought that this branch of the tree of life would be a terrific place to look for new models for comparative biology that could take advantage of the two strong model systems nearby. I was especially interested in studying how developmental mechanisms evolved in ways that produced diverse animal forms, and I figured that $C$. elegans and Drosophila could be rich and ongoing sources of information for comparative studies.

Tardigrades, better known as "water bears", are eightlegged microscopic animals (Fig. 12). These animals live just about everywhere, and remarkably, they survive desiccation, so they can be found readily by placing clean biological substrates such as mosses or lichens in spring water. We were fortunate that amateur scientist Bob McNuff had been growing water bear cultures continuously in his home for two decades [246], apparently overcoming historical difficulties with keeping cultures long-term [247], and he generously shared his culture methods. And another lab had begun to collect sequence data [248]. The species we had chosen, which Roberto Bertolani kindly identified for us as Hypsibius dujardini [246], has a short, two-week generation time, and is easy to keep as living cultures in the lab or as frozen stocks [246].

Our initial work was necessarily descriptive. $\mathrm{PhD}$ student Willow Gabriel and I observed and described embryonic development and started to build a cell lineage. We found that unequal cell divisions, nuclear migrations, and cell migrations occurred in stereotyped 


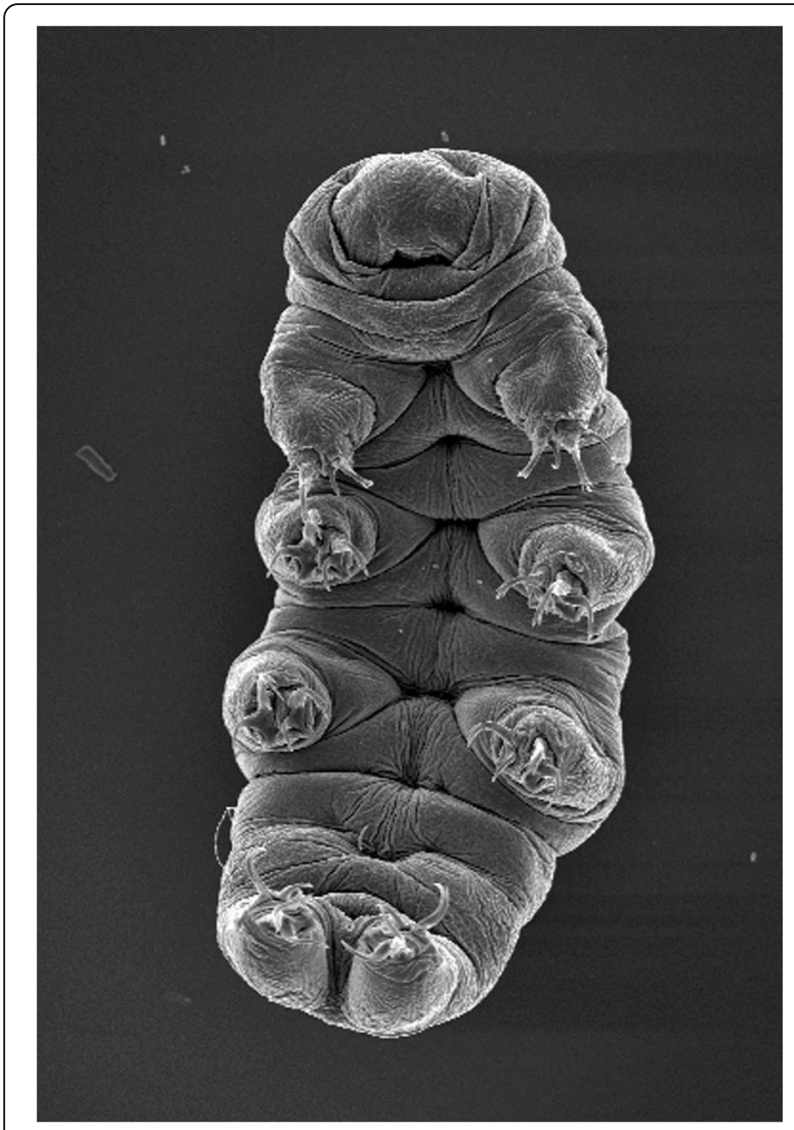

Fig. 12. Scanning electron micrograph of the water bear Hypsibius dujardini. Image credit: Vicky Madden and Bob Goldstein

patterns in each embryo [246]. And we began to develop tools, including methods for immunostaining and enzyme histochemical staining [246, 249]. Postdoc Jennifer Tenlen developed methods for RNA interference, which made feasible for the first time investigations into the functions of individual water bear genes [250]. We viewed these methods as forming a platform for investigating two topics: how developmental mechanisms evolve in ways that produce novel body plans, and how animals and biological materials more generally can survive in extreme environments.

Water bears are a convenient case study for asking how unique animal body plans arose because water bears share with arthropods highly modular body plans, composed of segments. This fact gave us some hope that homologous body parts could be recognized readily between water bears and organisms like Drosophila. Postdoc Frank Smith, who had developed in situ hybridization methods for water bears, has sought to understand how the compact body plan of water bears arose long ago, back when the major groups of animals had diverged. Frank found that the Hox genes that define the head segments of arthropods are expressed in the same anterior-to-posterior register in water bears-but throughout almost their entire body-leading the animals to be called at times "walking heads" [251, 252]. Water bears' compact bodies appear to have arisen by loss of a large part of an ancestral body plan, corresponding to the entire thorax and nearly the entire abdomen of Drosophila. This work revealed that animal body plans can arise by loss of a large body part, and a far larger part than we had anticipated [251]. How the finer, essential details of water bear anatomy first evolved and later diversified is not yet known. Work on these questions will likely benefit from Drosophila and C. elegans as sources for candidate mechanisms.

Water bears are among just five animal clades with representatives known to survive desiccation, together with certain arthropods, rotifers, nematodes, and flatworms [253]. Among these organisms, water bears have to date survived the most remarkable environmental extremes, including freezing in liquid nitrogen in the hydrated state, freezing to within a degree of absolute zero in the dried state, and more than 4000 grays of ionizing radiation in the dried or hydrated state [254]. In September 2007, desiccated water bears were launched in a Soyuz rocket and then exposed to the vacuum of space for 10 days. Upon rehydration, animals survived and produced young that hatched at normal or nearly normal rates $[255,256]$. Many of these extreme conditions should damage even what water bears and other organisms are made of-DNA, proteins, membranes-suggesting that water bears must produce protectants [254]. Postdoc Thomas Boothby sought to identify protectants, using transcriptome sequencing and RNA interference to identify essential protectants induced by extreme conditions, and then expressing the identified components in other kinds of cells to test for sufficiency to promote tolerance to extremes. This work has identified a set of water bear-specific proteins that promote desiccation tolerance [257]. Other groups have identified a water bear-specific chromatin-associated protein that can protect even human cultured cells from DNA damage [258]. Water bears may well serve as a continued source of a variety of molecules that can protect diverse molecular components against diverse kinds of extreme conditions.

Water bears have fairly complete and well-assembled genomes [258, 259]. Work using water bears would benefit tremendously at this stage from the development of methods to insert genes and edit the genome. In the meantime, there are many tools that can be applied to water bears, and other emerging models discussed in this Forum, to help unveil mechanisms of interest [260]. 


\section{Axolotls as models for regeneration Elly M. Tanaka}

How biological systems restore missing parts is fascinating at every level: at the level of cells, cellular aggregrates, and embryonic regulation; but perhaps the most remarkable example is the regeneration of the tetrapod limb as seen in salamanders including axolotls. Upon limb severing-which, as salamanders tend to be a carnivorous sort and eat each other's body parts, is not uncommon-the remaining cells jump into action to exquisitely replace each and every tissue type, including blood vessels, muscle, bone, nerve tracts, and skin, with the correct shape and function. How does this system work? Much of the tissue-scale logic of regeneration was worked out by capitalizing on the remarkable graftability of salamander tissues. For example, a limb blastema grafted to another body location still regenerates the limb it would have in situ, which showed us that the cells residing in the limb and tail have a memory of their position [261, 262]. Tissue-specific roles were defined by blocking regeneration through irradiation and then rescuing it with grafts of normal tissue, which, for example, gave the first indications that dermal cells play an important role in regeneration of patterned skeleton [263]. Molecular analysis proved challenging due to the need to work in adult tissue, but over time, all the required approaches to manipulate cell and molecular function have been developed, and it has been an exciting time to delve into the mechanisms of regeneration.

When choosing any model organism for research, one has to carefully consider why. I chose the axolotl as a model organism to study limb and spinal cord regeneration because it was one of the few species that was easily breedable in the laboratory, and therefore allowed for the development of transgenesis and, more recently, CRISPR-mediated gene mutation to study regeneration [264-268]. These genetic approaches are facilitated by the ability of the animals to lay up to 500 eggs per mating. Furthermore, several natural mutant strains exist, including those with absolutely no skin pigment. This allowed us to implement live imaging of fluorescent protein-expressing cells in larval axolotls to identify the cells that build the regenerate. Viral approaches to gene expression have also been very useful [269-272].

Several other features make the axolotl advantageous for tissue imaging studies. Due to the large genome, the cells are very large and therefore can be tracked using low magnification objectives with long working distances. This tissue is quite hardy, and is highly receptive to electroporation as a means of transfection. Furthermore, being cold-blooded, the animals can be kept at a variety of temperatures, including room temperature [273]. With the development of these molecular genetic and imaging capabilities, it has been possible to pinpoint the cells that form the blastema, and to start to identify and study the cues that initiate and sustain regeneration, as well as pattern the regenerate (Fig. 13).

Axolotls are certainly not the only experimental salamander system, with work in Cynops pyrroghaster, Pleurodeles Waltl, and Notophthalmus viridescens each bringing a different set of opportunities to understand regeneration biology and its diversity [274-277]. We have been astonished by the divergence in the implementation of skeletal muscle dedifferentiation as found in $N$. viridescens but not in axolotls, who use muscle stem cells to regenerate their muscle tissue [278].

I think that with the new developments in genome engineering that are available, it is a wonderful time for researchers to re-assess and survey metazoans, and look to Nature for those organisms that provide amplified traits that help us to solve biological questions. The axolotl is a great example of an organism that presents unique opportunities to study biology, that has a unique set of experimental advantages, and that has recently opened up to highly molecular, mechanistic approaches. It will be exciting to define further the genetic programs that convert cells from the adult state to the regeneration state while retaining their positional

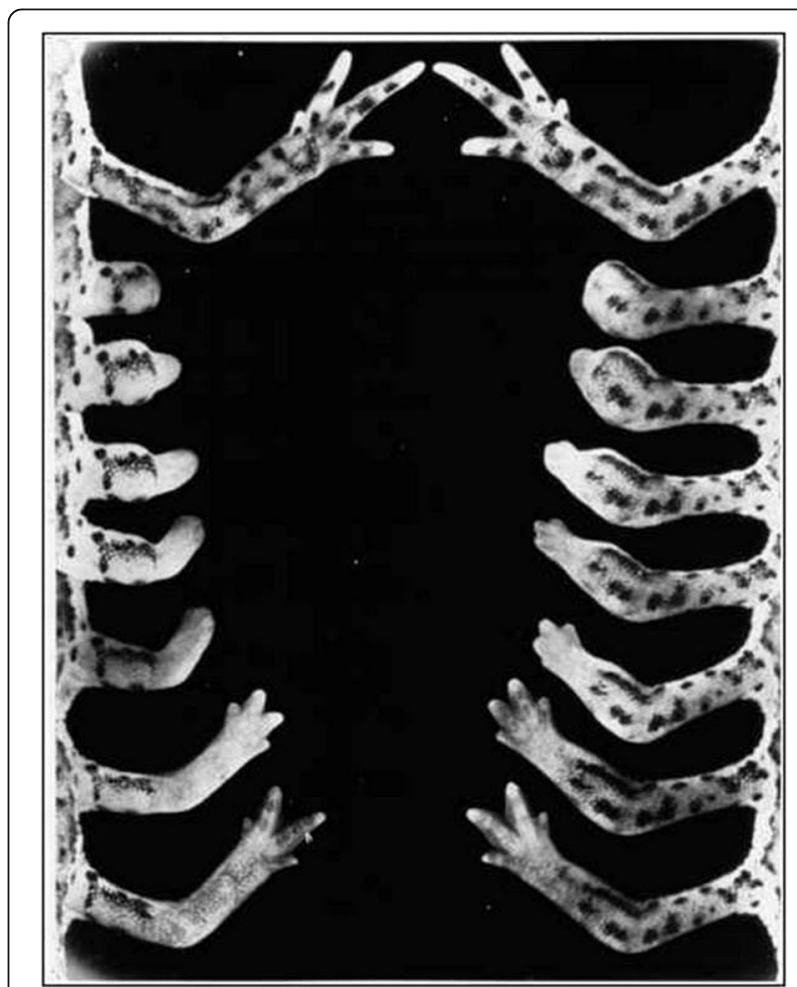

Fig. 13. Limb regeneration in salamanders. Reprinted from [328], Elsevier Books, Richard Goss, Principles of Regeneration, Copyright (1969), with permission from Elsevier 
memory, and to investigate the role of humoral factors, including the immune system, in this process.

\section{Stop the clock: the killifish model of aging in diapause \\ Chi-Kuo Hu and Anne Brunet \\ Aging biology and model organisms}

How do we age? This may be one of the most intriguing questions in biology. Aging is a progressive process that converts young and healthy individuals into old and decrepit ones, thereby limiting their lifespan. In nature, lifespan is an amazingly diverse trait, with maximal lifespans ranging from days in the medfly to over 500 years in clams [279]. This diversity opens up many possibilities for new model systems for aging and lifespan studies.

Much of our understanding of aging comes from studies of short-lived non-vertebrates (for example, $S$. cerevisiae, C. elegans, or Drosophila) [280-282]. While many key "aging genes" are evolutionarily conserved, the aging process in vertebrates is considerably more complex than in non-vertebrates. For example, nonvertebrates lack an adaptive immune system, which underlies many aspects of vertebrate aging via "immunosenescence" (gradual deterioration of the immune system during aging) [283] and "inflammaging" (chronic inflammation that occurs during aging) [284]. However, canonical vertebrate model organisms such as mice and zebrafish have relatively long lifespans (a maximum of $\sim 4$ and $\sim 5.5$ years in mice and zebrafish, respectively $[285,286])$. This is a critical experimental hurdle to study vertebrate aging.

To fill this gap, we and others have developed the African turquoise killifish Nothobranchius furzeri as a model organism for vertebrate aging [287-294]. The turquoise killifish is the shortest-lived vertebrate that can be bred in captivity, with a maximal lifespan of 7-8 months [288, 289] ( $\mathrm{C}-\mathrm{KH}$ and $\mathrm{AB}$, unpublished data). This is about an order of magnitude shorter than mice and zebrafish. Despite its short lifespan, the turquoise killifish recapitulates various stereotypical aging traits that have been reported in other vertebrates, including decline in normal functions and increased risk of diseases such as cancer [295-297].

\section{Lifecycle of the African turquoise killifish}

The short lifespan of the turquoise killifish is likely a consequence of an evolutionary adaption to its extreme habitat. The turquoise killifish naturally lives in ephemeral ponds in southeastern Africa, which entirely dry up during the dry season. This species switches between two distinct phases (Fig. 14) [298]. The first phase takes place during the rainy season and consists of a compressed lifecycle ( 40 days from embryos to embryos of the next generation), in which the turquoise killifish grows fast, reproduces fast, and, likely as a consequence of these constraints, also ages fast. The second phase takes place during the dry season and consists of a state

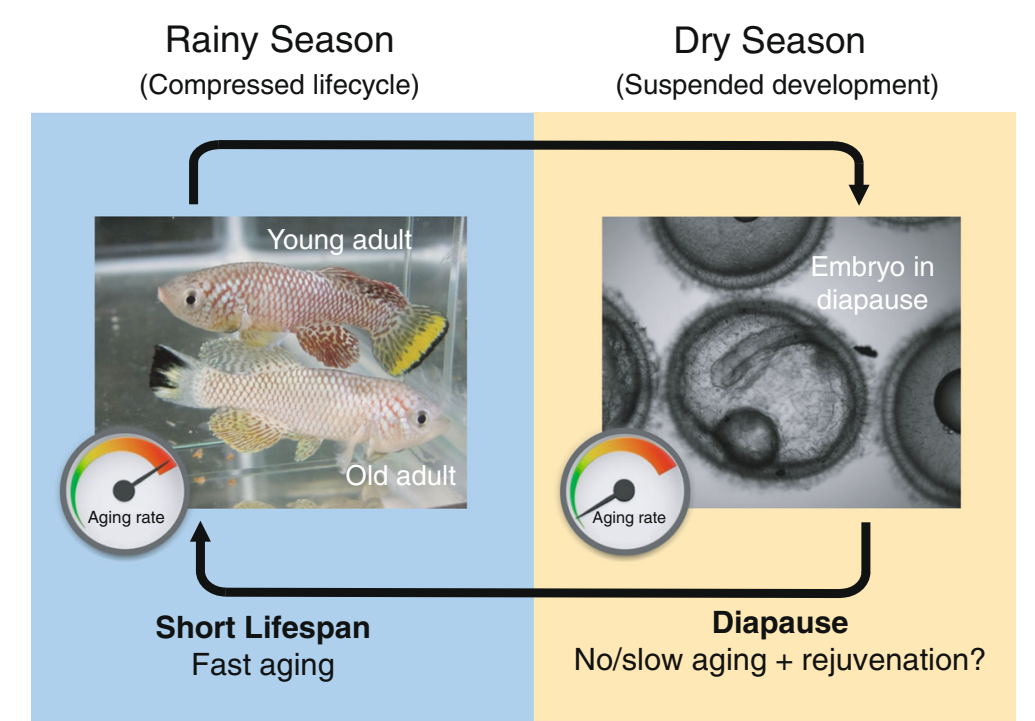

Fig. 14. The African turquoise killifish has two distinct phases in its lifecycle. During the rainy season, the turquoise killifish has a naturally compressed lifecycle. Turquoise killifish grow fast and rapidly reach sexual maturation, characterized by bright colors in males (Young adult). Old fish recapitulate aging phenotypes, including loss of muscle mass, color, and tissue homeostasis (Old adult). Newly laid turquoise killifish embryos enter diapause to survive the upcoming drought during the dry season (embryo). The embryos can stay in diapause for many months (several times longer than the fish lifespan), raising the possibility that the damage that accumulates with time may be slowed or even reset ("rejuvenation"). The embryos then break diapause and the fish resume their compressed lifecycle during the following rainy season. Some embryos escape diapause, and it is therefore possible to study each state separately in the laboratory 
of suspended development called diapause, which enables embryos laid during the rainy season to survive through the drought-lasting months or even years [299]. Notably, to hedge the risk, some embryos naturally skip diapause and exhibit a continuous lifecycle [300] ( $\mathrm{C}-\mathrm{KH}$ and $\mathrm{AB}$, unpublished data). This feature allows turquoise killifish colonies to be conveniently maintained in captivity without the hurdle of diapause [294]. In captivity, both phases of the lifecycle remain unchanged, even in constant water, indicating that both the short lifespan and diapause of this species are under genetic determination.

\section{Genetic and genomic resources of the African turquoise killifish}

Since the initial characterization, a comprehensive toolset to study killifish has been developed. This includes a standardized strain (in this case, GRZ [301]) - one of the critical features of a model organism. Several other strains are reaching the status of inbred lines $(\mathrm{C}-\mathrm{KH}$ and $\mathrm{AB}$, unpublished data), providing the community with additional options of genetic backgrounds, thereby minimizing the risk of strain-specific artifacts.

Great progress has also been made in developing genomic and genetic tools for this fish [294, 302-305]. We and the Platzer group have independently de novo assembled and annotated a reference genome for this fish [288, 289, 306, 307] along with numerous transcriptomic and epigenomic datasets [308-313]. An integrative reference genome generated by the NCBI pipeline with publicly available omics resources is available online (NCBI Genome ID 2642 [314]), and the effort to integrate the two genomes is currently ongoing. More recently, transgenesis and highly efficient CRISPR-Cas9 genome editing have been developed, with the ability to generate knockin or knockout lines in just 2 to 3 months [293, 302].

\section{Short lifespan and compressed lifecycle: unique features for lifespan studies}

A key hurdle for all lifespan studies is the need to control environmental variables throughout the whole lifespan of the organism. Longitudinal control of environmental variables can be challenging in canonical vertebrate model organisms such as mice, due to their longer lifespan, but it is easier in the turquoise killifish. In addition, relatively high throughput studies (for example, to test several genes or compounds simultaneously) are more feasible in the killifish, due to the low cost of maintaining a large cohort of animals. Finally, systematic longitudinal studies to predict individual lifespan trajectories are also more practical in the turquoise killifish than in longer-lived species [313].

\section{Diapause: another key feature of the African killifish}

In addition to the fast aging process of the turquoise killifish, which has clear values for vertebrate aging studies (reviewed extensively elsewhere [302]), the diapause phase of this fish provides a unique foray into a state that has features of "suspended animation". Diapause helps the species survive extreme stress such as drought, by timing the birth of offspring to more environmentally favorable conditions (such as the rainy season). Diapause phenomena are widespread throughout the animal kingdom, including mammals (for example, in roe deer and bats, which helps the species survive winter $[315,316])$. C. elegans also has several diapause-like states-notably the alternative developmental state called "dauer"which help the species survive a dearth of food [317]. It is interesting to note that in $C$. elegans, the regulatory network underlying the dauer state shares many components with that underlying aging $[318,319]$. In C. elegans or Drosophila, the period of time spent in diapause does not impact lifespan when these individuals reach adulthood (compared to individuals that did not go into diapause) [320-322]. This suggests that either no aging takes place during diapause or the damage caused by aging during this phase is corrected at the exit from diapause [323]. Thus, studying diapause could not only offer insight into the genetic network that regulates lifespan but also provide new ideas for prevention of damage accumulation or erasure of damage. However, due to the low embryo accessibility in mammals, diapause is vastly understudied in vertebrates. With its short lifespan and high embryo number and accessibility, the turquoise killifish is uniquely well-suited to study the relationship between diapause and aging and to understand how features of "suspended animation" could be harnessed.

\footnotetext{
Acknowledgements

J.J.R. and J.A.T.: Our research on diatoms is supported by a grant from the Gordon and Betty Moore Foundation.

P.S. and W.F.M. acknowledge the support of an American Cancer Society postdoctoral fellowship (PS) and NIH grant R01 GM113602.

L.F.L. thanks Tom Doak and Michael Lu for comments on the size of the macronucleus.

L. F-L.: I would like to thank Zac Cande and Scott Dawson for introducing me to Naegleria, and Chandler Fulton for teaching me nearly everything I know about our "wee friend." Thanks Chan!

J.K.P.: I would like to thank Pamela Silver for her support.

S.O.: I am grateful to E. Makeyev for suggestions on the manuscript, M. Makarova for the microscopy image, and Y. Gu for help with artwork. Our work is supported by a Wellcome Trust Senior Investigator Award (103741/Z/ 14/Z) to S.O.

T.G. and A.G.: We thank Anum Khan and Molly McQuilken for providing images for Fig. 7.

J.U.: I thank Gavriel Matt for comments on this article and for

photomicrographs. Work in my laboratory is supported by National Science Foundation grants MCB 1515220 and MCB 1616820.

M.B.: Thank you to Shu-Zon Wu who took the images in Fig. 9. I would also like to thank the Bezanilla lab for reading the document and Ana Maria Bezanilla for artistic advice. This was supported by a grant from the NSF to
} 
MB (MCB-1330171) and summer research fellowships from the Marine Biological Laboratory.

M.A.L. would like to thank members of the Lancaster laboratory for helpful comments. Work in the Lancaster laboratory is supported by the Medical Research Council MC_UP_1201/9, and a 3Rs prize from the National Centre for the Replacement, Refinement and Reduction of Animals in Research. S.H. and M.C.G: We thank Whitney J. Fropf from the Gibson lab for proofreading the manuscript. We also appreciate the helpful discussion all Gibson lab members provided during the writing of this review.

B.G.: Thanks to current and former lab members for brainstorming and for discoveries, and to the NSF for taking a risk in funding work on an unusual model. Water bear work in the lab has been supported by NSF grants IOS 1557432, IOS 1257320, and IOS 0235658.

E.M.T.: I would like to thank all the lab members and animal technicians who have worked in our lab over the years

C-K.H. and A.B.: We thank all members in the Brunet lab for helpful input and discussion. This work was supported by the National Institutes of Health $(\mathrm{NIH})$ DP1AG044848 and the Glenn Laboratories for the Biology of Aging (A.B.) and by the NIH T32 Cancer Biology Training Grant (5 T32 CA 9302-35) and the Life Science Research Foundation fellowships (C-K.H).

\section{Authors' contributions}

All authors read and approved the final version.

\section{Competing interests}

MAL is an inventor on patent applications describing the development of cerebral organoid methods.

\section{Publisher's Note}

Springer Nature remains neutral with regard to jurisdictional claims in published maps and institutional affiliations.

\section{Author details}

'Department of Biology, Howard Hughes Medical Institute Stanford University, Stanford, CA 94305, USA. ²Departments of Biochemistry and of Microbiology \& Immunology, Howard Hughes Medical Institute Stanford University, Stanford, CA 94305, USA. ${ }^{3}$ Department of Biochemistry \& Biophysics, University of California San Francisco, 600 16th St, San Francisco, CA 94158, USA. ${ }^{4}$ Departments of Biochemistry \& Molecular Biophysics and Biological Sciences, Columbia University, New York, NY 10032, USA. ${ }^{5}$ Department of Biology, University of Massachusetts, Amherst, MA 01003, USA. ${ }^{6}$ Visiting Scholar, Whitehead Institute, 9 Cambridge Center, Cambridge, MA 02142, USA. ${ }^{7}$ The Francis Crick Institute, 1 Midland Road, London NW1 1AT, UK. ${ }^{8}$ Randall Division of Cell and Molecular Biophysics, New Hunt's House, Guy's Campus, King's College London, London SE1 1UL, UK. ${ }^{9} 516$ Fordham Hall, University of North Carolina Chapel Hill, Chapel Hill, NC 27514 USA. ${ }^{10}$ Donald Danforth Plant Science Center, 975 N. Warson Rd, St. Louis, MO 63132, USA. ${ }^{11}$ MRC Laboratory of Molecular Biology, Cambridge Biomedical Campus, Francis Crick Avenue, CB2 0QH Cambridge, UK. ${ }^{12}$ Stowers Institute for Medical Research, Kansas City, MO 64110, USA. ${ }^{13}$ Department of Anatomy and Cell Biology, The University of Kansas School of Medicine, Kansas City, KS 66160, USA. ${ }^{14}$ Biology Department, The University of North Carolina at Chapel Hill, Chapel Hill, NC 27599, USA. ${ }^{15}$ Research Institute of Molecular Pathology (IMP), Vienna Biocenter (VBC), Campus Vienna Biocenter 1, 1030 Vienna, Austria. ${ }^{16}$ Department of Genetics, Stanford University, Stanford, CA 94305, USA. ${ }^{17}$ Glenn Laboratories for the Biology of Aging at Stanford, Stanford, CA 94305, USA.

\section{Published online: 29 June 2017}

\section{References}

1. Nelson DM, Tréguer P, Brzezinski MA, Leynaert A, Quéguiner B. Production and dissolution of biogenic silica in the ocean: Revised global estimates, comparison with regional data and relationship to biogenic sedimentation. Global Biogeochem Cycles. 1995;9(3):359-72.

2. Round FE, Crawford RM, Mann DG. Diatoms: Biology and Morphology of the Genera. UK: Cambridge University Press; 1990.

3. Tomas CR, Hasle GR. Identifying marine phytoplankton. USA: Academic Press; 1997.

4. Gambino M. Secretive Victorian Artists Made These Intricate Patterns Out of Algae. http://www.smithsonianmag.com/arts-culture/secretive- victorian-artists-made-these-intricate-patterns-out-of-algae-180952720/. Accessed 27 Jan 2017.

5. Simpson TL, Volcani BE, editors. Silicon and Siliceous Structures in Biological Systems. New York, NY: Springer New York; 1981.

6. Belcher AM, Wu XH, Christensen RJ, Hansma PK, Stucky GD, Morse DE. Control of crystal phase switching and orientation by soluble mollusc- shell proteins. Nature. 1996;381(6577):56-8.

7. Aizenberg J. Skeleton of Euplectella sp.: Structural Hierarchy from the Nanoscale to the Macroscale. Science. 2005;309(5732):275-8.

8. Crawford SA, Higgins MJ, Mulvaney P, Wetherbee R. Nanostructure of the diatom frustule as revealed by atomic force and scanning electron microscopy. J Phycol. 2001;37(4):543-54.

9. Kröger N, Lorenz S, Brunner E, Sumper M. Self-assembly of highly phosphorylated silaffins and their function in biosilica morphogenesis. Science. 2002;298(5593):584-6.

10. Tesson B, Hildebrand M, Brzezinski M, Stucky G, Morse D. Extensive and Intimate Association of the Cytoskeleton with Forming Silica in Diatoms: Control over Patterning on the Meso- and Micro-Scale. PLoS One. 2010; 5(12), e14300.

11. Cohn SA, Nash J, Pickett-Heaps JD. The effect of drugs on diatom valve morphogenesis. Protoplasma. 1989;149(2-3):130-43.

12. Armbrust EV, Berges JA, Bowler C, Green BR, Martinez D, Putnam NH, et al. The genome of the diatom Thalassiosira pseudonana: ecology, evolution, and metabolism. Science. 2004;306(5693):79-86.

13. Bowler C, Allen AE, Badger JH, Grimwood J, Jabbari K, Maheswari U, et al. The Phaeodactylum genome reveals the evolutionary history of diatom genomes. Nature. 2008;456:239-44.

14. Pseudo-nitzschia multiseries CLN-47. http://genome.jgi.doe.gov/Psemu1/ Psemu1.home.html. Accessed 27 Jan 2017.

15. Mock T, Otillar RP, Strauss J, McMullan M, Paajanen P, Schmutz J, et al. Evolutionary genomics of the cold-adapted diatom Fragilariopsis cylindrus. Nature. 2017;541(7638):536-40.

16. Miyahara M, Aoi M, Inoue-Kashino N, Kashino Y, Ifuku K. Highly Efficient Transformation of the Diatom Phaeodactylum tricornutum by Multi-Pulse Electroporation. Biosci Biotechnol Biochem. 2013;77(4):874-6.

17. Karas BJ, Diner RE, Lefebvre SC, McQuaid J, Phillips APR, Noddings CM, et al. Designer diatom episomes delivered by bacterial conjugation. Nat Commun. 2015;6:6925.

18. Scheffel A, Poulsen N, Shian S, Kröger N. Nanopatterned protein microrings from a diatom that direct silica morphogenesis. Proc Natl Acad Sci U S A. 2011;108(8):3175-80.

19. Hopes A, Nekrasov V, Kamoun S, Mock T. Editing of the urease gene by CRISPRCas in the diatom Thalassiosira pseudonana. Plant Methods. 2016;12(1):49.

20. Nymark M, Sharma AK, Sparstad T, Bones AM, Winge P. A CRISPR/Cas9 system adapted for gene editing in marine algae. Sci Rep. 2016;6(1):24951.

21. Kadono T, Miyagawa-Yamaguchi A, Kira N, Tomaru Y, Okami T, Yoshimatsu $T$, et al. Characterization of marine diatom-infecting virus promoters in the model diatom Phaeodactylum tricornutum. Sci Rep. 2015;5:1-13.

22. Gröger P, Poulsen N, Klemm J, Kröger N, Schlierf M. Establishing superresolution imaging for proteins in diatom biosilica. Sci Rep. 2016;6:36824.

23. Stonik V, Stonik I. Low-Molecular-Weight Metabolites from Diatoms: Structures, Biological Roles and Biosynthesis. Mar Drugs. 2015;13(6):3672-709.

24. Martin-Belmonte F, Perez-Moreno M. Epithelial cell polarity, stem cells and cancer. Nat Rev Cancer. 2011;12(1):23-38.

25. Morgan TH. Regeneration of proportionate structures in Stentor. Biol Bull. 1901;2(6):311-28.

26. de Terra N. Evidence for cortical control of macronuclear behavior inStentor. J Cell Physiol. 1971;78(3):377-85.

27. Tartar V. The biology of Stentor. Pergamon: Elsevier; 1961.

28. Tartar V. Extreme alteration of the nucleocytoplasmic ration in Stentor coeruleus. J Protozool. 1963;10:445-61.

29. Whitson GL. The effects of actinomycin $D$ and ribonuclease on oral regeneration in Stentor coeruleus. J Exp Zool. 1965;160(2):207-14.

30. Burchill BR. Synthesis of RNA and protein in relation to oral regeneration in the ciliateStentor coeruleus. J Exp Zool. 1968;167(4):427-38.

31. James EA. Regeneration and division in Stentor coeruleus: the effects of microinjected and externally applied actinomycin D and puromycin. Dev Biol. 1967;16(6):577-93.

32. Younger KB, Banerjee S, Kelleher JK, Winston M, Margulis L. Evidence that the Synchronized Production of New Basal Bodies is not Associated with Dna synthesis in Stentor coeruleus. J Cell Sci. 1972;11(2):621-37. 
33. Slabodnick MM, Ruby JG, Reiff SB, Swart EC, Gosai S, Prabakaran S, et al. The Macronuclear Genome of Stentor coeruleus Reveals Tiny Introns in a Giant Cell. Curr Biol. 2017;27(4):569-75.

34. Ellwood LC, Cowden RR. RNA metabolism during regeneration in Stentor coeruleus. Cytologia (Tokyo). 1966;31(1):80-8.

35. Randall JT, Jackson SF. Fine structure and function in Stentor polymorphous. J Biophys Biochem Cytol. 1958;4(6):807-30.

36. Slabodnick MM, Ruby JG, Dunn JG, Feldman JL, DeRisi JL, Marshall WF. The Kinase Regulator Mob1 Acts as a Patterning Protein for Stentor morphogenesis. PLoS Biol. 2014;12(5), e1001861.

37. Yu F-X, Guan K-L. The Hippo pathway: regulators and regulations. Genes Dev. 2013;27(4):355-71.

38. Chen X, Bracht JR, Goldman AD, Dolzhenko E, Clay DM, Swart EC, et al. The Architecture of a Scrambled Genome Reveals Massive Levels of Genomic Rearrangement during Development. Cell. 2014;158(5):1187-98.

39. Prescott DM. The DNA, of ciliated protozoa. Microbiol Rev. 1994;58(2):233-67.

40. Swart EC, Bracht JR, Magrini V, Minx P, Chen X, Zhou Y, et al. The Oxytricha trifallax Macronuclear Genome: A Complex Eukaryotic Genome with 16,000 Tiny Chromosomes. PLoS Biol. 2013;11(1), e1001473.

41. Gottschling DE, Zakian VA. Telomere proteins: specific recognition and protection of the natural termini of Oxytricha macronuclear DNA. Cell. 1986; 47(2):195-205.

42. Horvath MP, Schweiker VL, Bevilacqua JM, Ruggles JA, Schultz SC. Crystal structure of the Oxytricha nova telomere end binding protein complexed with single strand DNA. Cell. 1998;95(7):963-74.

43. Zoller SD, Hammersmith RL, Swart EC, Higgins BP, Doak TG, Herrick G, et al. Characterization and Taxonomic Validity of the Ciliate Oxytricha trifallax (Class Spirotrichea) Based on Multiple Gene Sequences: Limitations in Identifying Genera Solely by Morphology. Protist. 2012; 163(4):643-57.

44. Nowacki M, Vijayan V, Zhou Y, Schotanus K, Doak TG, Landweber LF. RNAmediated epigenetic programming of a genome-rearrangement pathway. Nature. 2008;451(7175):153-8.

45. Lindblad KA, Bracht JR, Williams AE, Landweber L. Thousands of RNAcached copies of whole chromosomes are present in the ciliate Oxytricha during development. RNA. 2017;rna.058511.116.

46. Fang W, Wang X, Bracht JR, Nowacki M, Landweber LF. Piwi-interacting RNAs protect DNA against loss during Oxytricha genome rearrangement. Cell. 2012;151(6):1243-55

47. Nowacki M, Higgins BP, Maquilan GM, Swart EC, Doak TG, Landweber LF. A functional role for transposases in a large eukaryotic genome. Science. 2009; 324(1996):935-8.

48. Jung S, Swart EC, Minx PJ, Magrini V, Mardis ER, Landweber LF, et al. Exploiting Oxytricha trifallax nanochromosomes to screen for non-coding RNA genes. Nucleic Acids Res. 2011;39(17):7529-47.

49. Nowacki M, Landweber LF. Epigenetic inheritance in ciliates. Curr Opin Microbiol. 2009:12(6):638-43.

50. Bracht JR, Wang X, Shetty K, Chen X, Uttarotai GJ, Callihan EC, et al. Chromosome fusions triggered by noncoding RNA. RNA Biol. 2017;14(5):620-31.

51. Fritz-Laylin LK, Prochnik SE, Ginger ML, Dacks JB, Carpenter ML, Field MC, et al. The Genome of Naegleria gruberi Illuminates Early Eukaryotic Versatility. Cell. 2010;140(5):631-42.

52. Fulton C. Naegleria: A Research Partner For Cell and Developmental Biology. J Eukaryot Microbiol. 1993;40(4):520-32.

53. Fulton C. Amebo-flagellates as research partners: the laboratory biology of naegleria and tetramitus. In: Prescott DM, editor. Methods Cell Physiol. 1970; 4:341-476.

54. Fulton C, Dingle AD. Basal bodies, but not centrioles, in Naegleria. J Cell Biol. 1971;51(3):826-36

55. Chung S, Cho J, Cheon H, Paik S, Lee J. Cloning and characterization of a divergent alpha-tubulin that is expressed specifically in dividing amebae of Naegleria gruberi. Gene. 2002;293(1-2):77-86.

56. King CA, Cooper L, Preston TM. Cell-substrate interactions during amoeboid locomotion ofNaegleria gruberi with special reference to alterations in temperature and electrolyte concentration of the medium. Protoplasma. 1983;118(1):10-8.

57. Lieber AD, Yehudai-Resheff S, Barnhart EL, Theriot JA, Keren K. Membrane tension in rapidly moving cells is determined by cytoskeletal forces. Curr Biol. 2013;23(15):1409-17.

58. Buenemann M, Levine H, Rappel W-J, Sander LM. The role of cell contraction and adhesion in dictyostelium motility. Biophys J. 2010;99(1):50-8.
59. Butler KL, Ambravaneswaran V, Agrawal N, Bilodeau M, Toner M, Tompkins $\mathrm{RG}$, et al. Burn injury reduces neutrophil directional migration speed in microfluidic devices. PLoS One. 2010;5(7): e11921.

60. Euteneuer U, Schliwa M. Persistent, directional motility of cells and cytoplasmic fragments in the absence of microtubules. Nature. 1984;310(5972):58-61.

61. Dziezanowski MA, DeStefano MJ, Rabinovitch M. Effect of antitubulins on spontaneous and chemotactic migration of neutrophils under agarose. J Cell Sci. 1980;42:379-88.

62. Paluch EK, Raz E. The role and regulation of blebs in cell migration. Curr Opin Cell Biol. 2013;25:582-90.

63. Lämmermann T, Sixt M. Mechanical modes of "amoeboid" cell migration. Curr Opin Cell Biol. 2009;21:636-44.

64. Rodriguez MA, LeClaire LL, Roberts TM. Preparing to move: assembly of the MSP amoeboid motility apparatus during spermiogenesis in Ascaris. Cell Motil Cytoskeleton. 2005;60(4):191-9.

65. Bergert M, Chandradoss SD, Desai R, Paluch E. Cell mechanics control rapid transitions between blebs and lamellipodia during migration. Proc Natl Acad Sci U S A. 2012;109(36):14434-9.

66. Yoshida K, Soldati T. Dissection of amoeboid movement into two mechanically distinct modes. J Cell Sci. 2006;119(Pt 18):3833-44.

67. Fulton $C$, Dingle AD. Appearance of the flagellate phenotype in populations of Naegleria amebae. Dev Biol. 1967;15(2):165-91.

68. Fulton C, Walsh C. Cell differentiation and flagellar elongation in Naegleria gruberi. Dependence on transcription and translation. J Cell Biol. 1980;85(2):346-60.

69. Dingle $A D$, Fulton C. Development of the flagellar apparatus of Naegleria. J Cell Biol. 1966;31(1):43-54.

70. Fritz-Laylin LK, Fulton C. Naegleria: a classic model for de novo basal body assembly. Cilia. 2016;5(1):10.

71. Fritz-Laylin LK, Assaf ZJ, Chen S, Cande WZ. Naegleria gruberi de novo basal body assembly occurs via stepwise incorporation of conserved proteins. Eukaryot Cell. 2010;9(6):860-5.

72. Lai EY, Walsh C, Wardell D, Fulton C. Programmed appearance of translatable flagellar tubulin mRNA during cell differentiation in Naegleria. Cell. 1979;17(4):867-78.

73. Levy YY, Lai EY, Remillard SP, Fulton C. Centrin is synthesized and assembled into basal bodies during Naegleria differentiation. Cell Motil Cytoskeleton. 1998;40(3):249-60.

74. Fritz-Laylin LK, Cande WZ. Ancestral centriole and flagella proteins identified by analysis of Naegleria differentiation. J Cell Sci. 2010;123(Pt 23):4024-31.

75. Khodjakov A, Rieder CL, Sluder G, Cassels G, Sibon O, Wang C-L. De novo formation of centrosomes in vertebrate cells arrested during $S$ phase. J Cell Biol. 2002;158(7):1171-81.

76. La Terra S, English CN, Hergert P, McEwen BF, Sluder G, Khodjakov A. The de novo centriole assembly pathway in HeLa cells: Cell cycle progression and centriole assembly/maturation. J Cell Biol. 2005;168(5):713-22.

77. Uetake Y, Lončarek J, Nordberg JJ, English CN, La Terra S, Khodjakov A, et al. Cell cycle progression and de novo centriole assembly after centrosomal removal in untransformed human cells. J Cell Biol. 2007;176(2):173-82.

78. Fritz-Laylin LK, Levy YY, Levitan E, Chen S, Cande WZ, Lai EY, et al. Rapid centriole assembly in $\mathrm{N}$ aegleria reveals conserved roles for both de novo and mentored assembly. Cytoskeleton. 2016;73(3):109-16.

79. Müller B, Groscurth S, Menzel M, Rüping BA, Twyman RM, Prüfer D, et al. Molecular and ultrastructural analysis of forisome subunits reveals the principles of forisome assembly. Ann Bot. 2014;113(7):1121-37.

80. Knoblauch M, Stubenrauch M, Van Bel AJE, Peters WS. Forisome performance in artificial sieve tubes. Plant, Cell Environ. 2012;35(8):1419-27.

81. Upadhyaya A, Baraban M, Wong J, Matsudaira P, van Oudenaarden A, Mahadevan L. Power-limited contraction dynamics of Vorticella convallaria: an ultrafast biological spring. Biophys J. 2008;94(1):265-72.

82. Raymann K, Bobay L-M, Doak TG, Lynch M, Gribaldo S. A genomic survey of Reb homologs suggests widespread occurrence of R-bodies in proteobacteria. G3 (Bethesda). 2013;3:505-16.

83. Sonneborn TM. Gene and cytoplasm. Proc Natl Acad Sci U S A. 1943;29(11):329-38

84. Dippell RV. The Fine Structure of Kappa in Killer Stock 51 of Paramecium aurelia; preliminary observations. J Biophys Biochem Cytol. 1958;4(1):125-8.

85. Mueller JA. Vitally stained kappa in Paramecium aurelia. J Exp Zool. 1965; 160(3):369-72

86. Quackenbush RL, Burbach JA. Cloning and expression of DNA sequences associated with the killer trait of Paramecium tetraurelia stock 47. Proc Natl Acad Sci U S A. 1983:80(1):250-4. 
87. Heruth DP, Pond FR, Dilts JA, Quackenbush RL. Characterization of genetic determinants for $\mathrm{R}$ body synthesis and assembly in Caedibacter taeniospiralis 47 and 116. J Bacteriol. 1994;176(12):3559-67.

88. Kanabrocki JA, Quackenbush RL, Pond FR. Organization and expression of genetic determinants for synthesis and assembly of type $51 \mathrm{R}$ bodies. J Bacteriol. 1986;168(1):40-8.

89. Polka JK, Silver PA. A Tunable Protein Piston That Breaks Membranes to Release Encapsulated Cargo. ACS Synth Biol. 2016;5(4):303-11.

90. Drechsler H, McAinsh AD. Exotic mitotic mechanisms. Open Biol. 2012; 2(12):120140.

91. Makarova M, Oliferenko S. Mixing and matching nuclear envelope remodeling and spindle assembly strategies in the evolution of mitosis. Curr Opin Cell Biol. 2016;41:43-50

92. Oliferenko S, Chew TG, Balasubramanian MK. Positioning cytokinesis. Genes and Dev. 2009:23:660-74.

93. Ungricht R, Kutay U. Mechanisms and functions of nuclear envelope remodelling. Nat Rev Mol Cell Biol. 2017;18(4):229-45.

94. Zhang D, Oliferenko S. Remodeling the nuclear membrane during closed mitosis. Curr Opin Cell Biol. 2013;25:1-7.

95. Rhind N, Chen Z, Yassour M, Thompson DA, Haas BJ, Habib N, et al. Comparative functional genomics of the fission yeasts. Science. 2011;332(6032):930-6.

96. Yam C, He Y, Zhang D, Chiam KH, Oliferenko S. Divergent strategies for controlling the nuclear membrane satisfy geometric constraints during nuclear division. Curr Biol. 2011;21(15):1314-9.

97. Aoki K, Hayashi H, Furuya K, Sato M, Takagi T, Osumi M, et al. Breakage of the nuclear envelope by an extending mitotic nucleus occurs during anaphase in Schizosaccharomyces japonicus. Genes Cells. 2011;16(9):911-26.

98. Makarova M, Gu Y, Chen JS, Beckley JR, Gould KL, Oliferenko S. Temporal Regulation of Lipin Activity Diverged to Account for Differences in Mitotic Programs. Curr Biol. 2016;26(2):237-43.

99. Fujita I, Nishihara Y, Tanaka M, Tsujii H, Chikashige Y, Watanabe Y, et al. Telomere-nuclear envelope dissociation promoted by rap1 phosphorylation ensures faithful chromosome segregation. Curr Biol. 2012;22(20):1932-7.

100. Hediger F, Neumann FR, Van Houwe G, Dubrana K, Gasser SM. Live imaging of telomeres: $y K u$ and Sir proteins define redundant telomere-anchoring pathways in yeast. Curr Biol. 2002;12(24):2076-89.

101. Yam C, Gu Y, Oliferenko S. Partitioning and remodeling of the Schizosaccharomyces japonicus mitotic nucleus require chromosome tethers. Curr Biol. 2013;23(22):2303-10.

102. Lemaitre JM, Géraud G, Méchali M. Dynamics of the genome during early Xenopus laevis development: Karyomeres as independent units of replication. J Cell Biol. 1998;142(5):1159-66.

103. Abrams EW, Zhang H, Marlow FL, Kapp L, Lu S, Mullins MC. Dynamic assembly of brambleberry mediates nuclear envelope fusion during early development. Cell. 2012;150(3):521-32.

104. Ulbert S, Antonin W, Platani M, Mattaj IW. The inner nuclear membrane protein Lem2 is critical for normal nuclear envelope morphology. FEBS Lett. 2006;580(27):6435-41.

105. Barkan R, Zahand AJ, Sharabi K, Lamm AT, Feinstein N, Haithcock E, et al. Ce-emerin and LEM-2: essential roles in Caenorhabditis elegans development, muscle function, and mitosis. Mol Biol Cell. 2012;23(4):543-52.

106. Gonzalez Y, Saito A, Sazer S. Fission yeast Lem2 and Man1 perform fundamental functions of the animal cell nuclear lamina. Nucleus. 2012;3(1):60-76.

107. Gu Y, Yam C, Oliferenko S. Rewiring of cellular division site selection in evolution of fission yeasts. Curr Biol. 2015;25(9):1187-94.

108. Gu Y, Oliferenko S. Comparative biology of cell division in the fission yeast clade. Curr Opin Microbiol. 2015;28:18-25.

109. Huang J, Chew TG, Gu Y, Palani S, Kamnev A, Martin DS, et al. Curvatureinduced expulsion of actomyosin bundles during cytokinetic ring contraction. Elife. 2016;5:e21383.

110. Furuya $\mathrm{K}$, Niki H. Isolation of heterothallic haploid and auxotrophic mutants of Schizosaccharomyces japonicus. Yeast. 2009;26(4):221-33.

111. Aoki K, Nakajima R, Furuya K, Niki H. Novel episomal vectors and a highly efficient transformation procedure for the fission yeast Schizosaccharomyces japonicus. Yeast. 2010;27(12):1049-60.

112. Furuya K, Niki H. Hyphal differentiation induced via a DNA damage checkpoint-dependent pathway engaged in crosstalk with nutrient stress signaling in Schizosaccharomyces japonicus. Curr Genet. 2012;58(5-6):291-303.

113. Okamoto S, Furuya K, Nozaki S, Aoki K, Niki H. Synchronous activation of cell division by light or temperature stimuli in the dimorphic yeast Schizosaccharomyces japonicus. Eukaryot Cell. 2013;12(9):1235-43.
114. Bulder CJEA. On respiratory deficiency in yeasts. The Netherlands: TU Left; 1963.

115. Upadhyay U, Srivastava S, Khatri I, Nanda JS, Subramanian S, Arora A, et al. Ablation of RNAi and retrotransposons accompany acquisition and evolution of transposases to heterochromatin protein CENPB. Mol Biol Cell. 2017; doi: 10.1091/mbc.E16-07-0485.

116. Chen YE, Tropini C, Jonas K, Tsokos CG, Huang KC, Laub MT. Spatial gradient of protein phosphorylation underlies replicative asymmetry in a bacterium. Proc Natl Acad Sci U S A. 2011;108(3):1052-7.

117. Lécuyer E, Yoshida H, Parthasarathy N, Alm C, Babak T, Cerovina T, et al. Global analysis of mRNA Localization Reveals a Prominent Role in Organizing Cellular Architecture and Function. Cell. 2007;131(1):174-87.

118. Dietrich FS, Voegeli S, Kuo S, Philippsen P. Genomes of Ashbya fungi isolated from insects reveal four mating-type loci, numerous translocations, lack of transposons, and distinct gene duplications. G3 (Bethesda). 2013;3:1225-39.

119. Schmitz HP, Philippsen P. Evolution of multinucleated Ashbya gossypii hyphae from a budding yeast-like ancestor. Fungal Biol. 2011;115(6):557-68.

120. Dietrich FS, Voegeli S, Brachat S, Lerch A, Gates K, Steiner S, et al. The Ashbya gossypii genome as a tool for mapping the ancient Saccharomyces cerevisiae genome. Science. 2004;304(5668):304-7.

121. Wright MC, Philippsen P. Replicative transformation of the filamentous fungus Ashbya gossypii with plasmids containing Saccharomyces cerevisiae ARS elements. Gene. 1991;109(1):99-105.

122. Steiner S, Wendland J, Wright MC, Philippsen P. Homologous recombination as the main mechanism for DNA integration and cause of rearrangements in the filamentous ascomycete Ashbya gossypii. Genetics. 1995;140(3):973-87.

123. Wendland J, Ayad-Durieux Y, Knechtle P, Rebischung C, Philippsen P. PCRbased gene targeting in the filamentous fungus Ashbya gossypii. Gene. 2000;242(1-2):381-91.

124. Wendland J, Walther A. Ashbya gossypii: a model for fungal developmental biology. Nat Rev Microbiol. 2005;3(5):421-9.

125. Lee $\mathrm{CH}$, Zhang H, Baker AE, Occhipinti P, Borsuk ME, Gladfelter AS. Protein aggregation behavior regulates cyclin transcript localization and cell-cycle control. Dev Cell. 2013;25(6):572-84.

126. Zhang H, Elbaum-Garfinkle S, Langdon EM, Taylor N, Occhipinti P, Bridges AA, et al. RNA Controls PolyQ Protein Phase Transitions. Mol Cell. 2015;60(2):220-30

127. Lee $\mathrm{CH}$, Occhipinti P, Gladfelter AS. PolyQ-dependent RNA-protein assemblies control symmetry breaking. J Cell Biol. 2015;208(5):533-44.

128. Szathmáry E, Smith JM. The major evolutionary transitions. Nature. 1995; 374:227-32.

129. Bonner JT. The origins of multicellularity. Integr Biol. 1998;1 (1):27-36.

130. King N. The unicellular ancestry of animal development. Dev Cell. 2004;7:313-25.

131. Grosberg RK, Strathmann RR. The Evolution of Multicellularity: A Minor Major Transition? Annu Rev Ecol Evol Syst. 2007;38:621-54.

132. Matt G, Umen J. Volvox: A simple algal model for embryogenesis, morphogenesis and cellular differentiation. Dev Biol. 2016;419:99-113.

133. Herron MD, Hackett JD, Aylward FO, Michod RE. Triassic origin and early radiation of multicellular volvocine algae. Proc Natl Acad Sci U S A. 2009;106(9):3254-8.

134. Harris EH. Chlamydomonas as a model organism. Annu Rev Plant Physiol Plant Mol Biol. 2001;52:363-406.

135. Umen JG, Olson BJSC. Genomics of Volvocine Algae. Adv Bot Res. 2012; 64:185-243.

136. Starr RC. Control of differentiation in Volvox. Soc Dev Biol. 1970;29:59-100.

137. Kirk DL. Volvox: molecular-genetic origins of multicellularity and cellular differentiation. UK: Cambridge University Press; 1998.

138. van Leeuwenhoek A. Part of a letter from Mr Antony van Leeuwenhoek, concerning the Worms in Sheeps Livers, Gnats, and Animalcula in the Excrements of Frogs. Philos Trans R Soc Lond. 1700;22(260-276):509-18.

139. Kirk DL. A twelve-step program for evolving multicellularity and a division of labor. BioEssays. 2005;27:299-310.

140. Merchant SS, Prochnik SE, Vallon O, Harris EH, Karpowicz SJ, Witman GB, et al. The Chlamydomonas genome reveals the evolution of key animal and plant functions. Science. 2007:318(5848):245-50.

141. Prochnik SE, Umen J, Nedelcu AM, Hallmann A, Miller SM, Nishii I, et al. Genomic analysis of organismal complexity in the multicellular green alga Volvox carteri. Science. 2010;329(5988):223-6.

142. Hanschen ER, Marriage TN, Ferris PJ, Hamaji T, Toyoda A, Fujiyama A, et al. The Gonium pectorale genome demonstrates co-option of cell cycle regulation during the evolution of multicellularity. Nat Commun. 2016;7:11370. 
143. Nishii I, Miller SM. Volvox: simple steps to developmental complexity? Curr Opin Plant Biol. 2010;13:646-53

144. Huskey R, Griffin B, Cecil P, Callahan A. A Preliminary Genetic Investigation of Volvox Carteri. Genetics. 1979;91(2):229-44.

145. Umen JG. Evolution of sex and mating loci: An expanded view from Volvocine algae. Curr Opin Microbiol. 2011;14:634-41.

146. Miller SM, Schmitt R, Kirk DL. Jordan, an active Volvox transposable element similar to higher plant transposons. Plant Cell. 1993;5(9):1125-38.

147. Ueki N, Nishii I. Idaten is a new cold-inducible transposon of Volvox carter that can be used for tagging developmentally important genes. Genetics. 2008;180(3):1343-53.

148. Ishida K. Vectorette PCR-primed transposon display using the Jordan transposon in Volvox carteri: an efficient tool that analyzes more than 300 Jordan-derived PCR Fragments to retrieve tagged genes. Protist. 2008;159(1):5-19.

149. Geng S, De Hoff P, Umen JG, Callahan A, Gruber H. Evolution of Sexes from an Ancestral Mating-Type Specification Pathway. PLoS Biol. 2014;12(7): e1001904.

150. Schiedlmeier B, Schmitt R, Müller W, Kirk MM, Gruber H, Mages W, et al. Nuclear transformation of Volvox carteri. Proc Natl Acad Sci U S A. 1994; 91(11):5080-4.

151. Jakobiak T, Mages W, Scharf B, Babinger P, Stark K, Schmitt R. The bacterial paromomycin resistance gene, aphH, as a dominant selectable marker in Volvox carteri. Protist. 2004;155:381-93.

152. Hallmann A, Sumper M. The Chlorella hexose/H+ symporter is a useful selectable marker and biochemical reagent when expressed in Volvox. Proc Natl Acad Sci U S A. 1996;93(2):669-73.

153. Ishida K. Sexual pheromone induces diffusion of the pheromone-homologous polypeptide in the extracellular matrix of Volvox carteri. Eukaryot Cell. 2007; 6(11):2157-62.

154. Pappas V, Miller SM. Functional analysis of the Volvox carteri asymmetric division protein GlsA. Mech Dev. 2009;126(10):842-51.

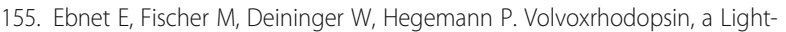
Regulated Sensory Photoreceptor of the Spheroidal Green Alga Volvox carteri. Plant Cell. 1999;11:1473-84.

156. Cheng Q, Hallmann A, Edwards L, Miller SM. Characterization of a heat-shockinducible hsp70 gene of the green alga Volvox carteri. Gene. 2006;371(1):112-20.

157. Baek K, Kim DH, Jeong J, Sim SJ, Melis A, Kim J-S, et al. DNA-free two-gene knockout in Chlamydomonas reinhardtii via CRISPR-Cas9 ribonucleoproteins. Sci Rep. 2016;6:30620.

158. Shin S-E, Lim J-M, Koh HG, Kim EK, Kang NK, Jeon S, et al. CRISPR/Cas9induced knockout and knock-in mutations in Chlamydomonas reinhardtii. Sci Rep. 2016;6:27810.

159. Höhn S, Honerkamp-Smith AR, Haas PA, Trong PK, Goldstein RE. Dynamics of a Volvox embryo turning itself inside out. Phys Rev Lett. 2015;114(17):178101.

160. Kodama Y. Time gating of chloroplast autofluorescence allows clearer fluorescence imaging in planta. PLoS One. 2016;11(3):e0152484.

161. Kirk MM, Ransick A, McRae SE, Kirk DL. The relationship between cell size and cell fate in Volvox carteri. J Cell Biol. 1993;123(1):191-208.

162. Nakazawa A, Nishii I. Amidic and acetonic cryoprotectants improve cryopreservation of volvocine green algae. Cryo Lett. 2012;33(3):202-13.

163. Chlamydomonas Center Meeting Announcements. http://www. chlamycollection.org/category/meetings/. Accessed 15 Mar 2017.

164. Volvox 2017 http://www.volvox2017.org/. Accessed 15 Mar 2017.

165. Cove DJ, Schild A, Ashton NW, Hartmann E. Genetic and physiological studies of light on the development of the moss Physcomitrella patens. Photochem Photobiol. 1978;27(2):249-54.

166. Harrison CJ, Roeder AHK, Meyerowitz EM, Langdale JA. Local Cues and Asymmetric Cell Divisions Underpin Body Plan Transitions in the Moss Physcomitrella patens. Curr Biol. 2009;19(6):461-71.

167. Bascom CS, Wu S-Z, Nelson K, Oakey J, Bezanilla M. Long-Term Growth of Moss in Microfluidic Devices Enables Subcellular Studies in Development. Plant Physiol. 2016;172(1):28-37.

168. Schaefer D, Zryd JP, Knight CD, Cove DJ. Stable transformation of the moss Physcomitrella patens. MGG Mol Gen Genet. 1991;226(3):418-24.

169. Kammerer W, Cove DJ. Genetic analysis of the effects of re-transformation of transgenic lines of the moss Physcomitrella patens. Mol Gen Genet. 1996; 250(3):380-2.

170. Schaefer DG, Zryd J-P. Efficient gene targeting in the moss Physcomitrella patens. Plant J. 1997;11(6):1195-206.

171. Strepp R, Scholz S, Kruse S, Speth V, Reski R. Plant nuclear gene knockout reveals a role in plastid division for the homolog of the bacterial cell division protein FtsZ, an ancestral tubulin. Proc Natl Acad Sci U S A. 1998; 95(8):4368-73.

172. Sakakibara K, Nishiyama T, Sumikawa N, Kofuji R, Murata T, Hasebe M. Involvement of auxin and a homeodomain-leucine zipper I gene in rhizoid development of the moss Physcomitrella patens. Development. 2003; 130(20):4835-46.

173. Perroud PF, Cove DJ, Quatrano RS, Mcdaniel SF. An experimental method to facilitate the identification of hybrid sporophytes in the moss Physcomitrella patens using fluorescent tagged lines. New Phytol. 2011;191(1):301-6.

174. Collonnier C, Epert A, Mara K, Maclot F, Guyon-Debast A, Charlot F, et al. CRISPR-Cas9-mediated efficient directed mutagenesis and RAD51dependent and RAD51-independent gene targeting in the moss Physcomitrella patens. Plant Biotechnol J. 2016;15(1):122-31.

175. Lopez-Obando M, Hoffmann B, Géry C, Guyon-Debast A, Téoulé E, Rameau C, et al. Simple and Efficient Targeting of Multiple Genes Through CRISPRCas9 in Physcomitrella patens. G3 (Bethesda). 2016:6(11):3647-53.

176. Bezanilla M, Perroud PF, Pan A, Klueh P, Quatrano RS. An RNAi system in Physcomitrella patens with an internal marker for silencing allows for rapid identification of loss of function phenotypes. Plant Biol. 2005;7(3):251-7.

177. Bezanilla M, Pan A, Quatrano RS. RNA interference in the moss Physcomitrella patens. Plant Physiol. 2003;133:470-4.

178. Nakaoka Y, Miki T, Fujioka R, Uehara R, Tomioka A, Obuse C, et al. An inducible RNA interference system in Physcomitrella patens reveals a dominant role of augmin in phragmoplast microtubule generation. Plant Cell. 2012;24(4):1478-93.

179. Stevenson SR, Kamisugi Y, Trinh CH, Schmutz J, Jenkins JW, Grimwood J, et al. Genetic analysis of Physcomitrella patens identifies ABSCISIC ACID NON-RESPONSIVE (ANR), a regulator of ABA responses unique to basal land plants and required for desiccation tolerance. Plant Cell. 2016;28(6):1310-27.

180. Herculano-Houzel S. The human brain in numbers: a linearly scaled-up primate brain. Front Hum Neurosci. 2009;3:31.

181. DeFelipe J. The evolution of the brain, the human nature of cortical circuits, and intellectual creativity. Front Neuroanat. 2011;5:29.

182. Ballesteros Yáñez I, Muñoz A, Contreras J, Gonzalez J, Rodriguez-Veiga E, DeFelipe J. Double bouquet cell in the human cerebral cortex and a comparison with other mammals. J Comp Neurol. 2005;486(4):344-60.

183. Raghanti MA, Spocter MA, Stimpson CD, Erwin JM, Bonar CJ, Allman JM, et al. Species-specific distributions of tyrosine hydroxylase-immunoreactive neurons in the prefrontal cortex of anthropoid primates. Neuroscience. 2009;158(4):1551-9.

184. Benavides-Piccione R, Ballesteros-Yáñez I, DeFelipe J, Yuste R. Cortical area and species differences in dendritic spine morphology. J Neurocytol. 2002 31(3-5 SPEC. ISS):337-46.

185. Mahmood S, Ahmad W, Hassan MJ. Autosomal recessive primary microcephaly (MCPH): clinical manifestations, genetic heterogeneity and mutation continuum. Orphanet J Rare Dis. 2011;6(1):39.

186. LaFerla FM, Green KN. Animal models of Alzheimer disease. Cold Spring Harb Perspect Med. 2012;2(11):a006320.

187. Friedman RA. A dry pipeline for psychiatric drugs. The New York Times. 2013. http://www.nytimes.com/2013/08/20/health/a-dry-pipeline-forpsychiatric-drugs.html. Accessed 15 Mar 2017.

188. Zhang S-C, Wernig M, Duncan ID, Brüstle O, Thomson JA. In vitro differentiation of transplantable neural precursors from human embryonic stem cells. Nat Biotechnol. 2001;19(12):1129-33.

189. Shi Y, Kirwan P, Smith J, Robinson HPC, Livesey FJ. Human cerebral cortex development from pluripotent stem cells to functional excitatory synapses. Nat Neurosci. 2012;15(3):477-86. S1.

190. Chambers SM, Fasano CA, Papapetrou EP, Tomishima M, Sadelain M, Studer L. Highly efficient neural conversion of human ES and iPS cells by dual inhibition of SMAD signaling. Nat Biotechnol. 2009;27(3):275-80.

191. Eiraku M, Watanabe K, Matsuo-Takasaki M, Kawada M, Yonemura S, Matsumura $M$, et al. Self-Organized Formation of Polarized Cortical Tissues from ESCs and Its Active Manipulation by Extrinsic Signals. Cell Stem Cell. 2008;3(5):519-32.

192. Lancaster MA, Renner M, Martin C-A, Wenzel D, Bicknell LS, Hurles ME, et al. Cerebral organoids model human brain development and microcephaly. Nature. 2012;501(1):373-9.

193. Kadoshima T, Sakaguchi H, Nakano T, Soen M, Ando S, Eiraku M, et al. Selforganization of axial polarity, inside-out layer pattern, and species-specific progenitor dynamics in human ES cell-derived neocortex. Proc Natl Acad Sci U S A. 2013;110(50):20284-9. 
194. Paşca AM, Sloan SA, Clarke LE, Tian Y, Makinson CD, Huber N, et al. Functional cortical neurons and astrocytes from human pluripotent stem cells in 3D culture. Nat Methods. 2015;12(7):671-8.

195. Kelava I, Lancaster MA. Stem Cell Models of Human Brain Development. Cell Stem Cell. 2016;18:736-48.

196. Otani T, Marchetto MC, Gage FH, Simons BD, Livesey FJ. 2D and 3D Stem Cell Models of Primate Cortical Development Identify Species-Specific Differences in Progenitor Behavior Contributing to Brain Size. Cell Stem Cell. 2016;18(4):467-80.

197. Mora-Bermúdez F, Badsha F, Kanton S, Camp JG, Vernot B, Köhler K, et al. Differences and similarities between human and chimpanzee neural progenitors during cerebral cortex development. Elife. 2016;5.

198. Mariani J, Coppola G, Zhang P, Abyzov A, Provini L, Tomasini L, et al. FOXG1-Dependent Dysregulation of GABA/Glutamate Neuron Differentiation in Autism Spectrum Disorders. Cell. 2015;162(2):375-90.

199. Bershteyn M, Nowakowski TJ, Pollen AA, Di Lullo E, Nene A, Wynshaw-Boris A, et al. Human iPSC-Derived Cerebral Organoids Model Cellular Features of Lissencephaly and Reveal Prolonged Mitosis of Outer Radial Glia. Cell Stem Cell. 2017;20(4):435-49.e4.

200. Qian X, Nguyen HN, Song MM, Hadiono C, Ogden SC, Hammack C, et al. Brain-Region-Specific Organoids Using Mini-bioreactors for Modeling ZIKV Exposure. Cell. 2016;165(5):1238-54.

201. Cugola FR, Fernandes IR, Russo FB, Freitas BC, Dias JLM, Guimarães KP, et al. The Brazilian Zika virus strain causes birth defects in experimental models. Nature. 2016;534(7606):267-71.

202. Lenhoff SG, Lenhoff HM, Trembley A. Hydra and the birth of experimental biology, 1744: Abraham Trembley's Mémoires concerning the polyps. Pacific Grove: Boxwood Press; 1986.

203. Haeckel E. Art forms from the ocean : the radiolarian atlas of 1862 , Munich; London: Prestel; 2005.

204. Hyman LH. The invertebrates. 1st ed. McGraw-Hill publications in the zoological sciences. New York: McGraw-Hill; 1940.

205. Muscatine L, Lenhoff HM. Coelenterate biology: reviews and new perspectives. New York: Academic Press; 1974.

206. Stephenson TA. The British sea anemones. 1935.

207. Wells S, Pyle RM, Collins NM, IUCN Conservation Monitoring Centre. International Union for Conservation of Nature and Natural Resources., International Union for Conservation of Nature and Natural Resources. Species Survival Commission. The IUCN invertebrate red data book. Gland: IUCN; 1983.

208. Hand C, Uhlinger KR. The Culture, Sexual and Asexual Reproduction, and Growth of the Sea Anemone Nematostella vectensis. Biol Bull. 1992;182(2):169-76.

209. Bridge D, Cunningham CW, DeSalle R, Buss LW. Class-level relationships in the phylum Cnidaria: molecular and morphological evidence. Mol Biol Evol. 1995;12(4):679-89.

210. Kayal E, Roure B, Philippe H, Collins AG, Lavrov DV. Cnidarian phylogenetic relationships as revealed by mitogenomics. BMC Evol Biol. 2013;13:5.

211. Brusca RC, Brusca GJ. Invertebrates. Sunderland, Mass: Sinauer Associates; 1990.

212. Bridge D, Cunningham CW, Schierwater B, DeSalle R, Buss LW. Class-level relationships in the phylum Cnidaria: evidence from mitochondrial genome structure. Proc Natl Acad Sci U S A. 1992;89(18):8750-3.

213. Marques AC, Collins AG. Cladistic analysis of Medusozoa and cnidarian evolution. Invertebr Biol. 2004;123(1):23-42.

214. Darling JA, Reitzel AR, Burton PM, Mazza ME, Ryan JF, Sullivan JC, et al. Rising starlet: the starlet sea anemone, Nematostella vectensis. Bioessays. 2005;27(2):211-21.

215. Collins AG. Phylogeny of Medusozoa and the evolution of cnidarian life cycles. J Evol Biol. 2002;15(3):418-32. Blackwell Science Ltd.

216. Loya Y, Sakai K. Bidirectional sex change in mushroom stony corals. Proc Biol Sci. 2008;275(1649):2335-43.

217. Schlesinger A, Kramarsky-Winter E, Rosenfeld H, Armoza-Zvoloni R, Loya Y. Sexual plasticity and self-fertilization in the sea anemone Aiptasia diaphana. PLoS One. 2010;5(7):e11874.

218. Fritzenwanker $\mathrm{JH}$, Technau U. Induction of gametogenesis in the basal cnidarian Nematostella vectensis(Anthozoa). Dev Genes Evol. 2002;212(2):99-103.

219. Genikhovich G, Technau U. Induction of spawning in the starlet sea anemone Nematostella vectensis, in vitro fertilization of gametes, and dejellying of zygotes. Cold Spring Harb Protoc. 2009;2009(9):pdb prot5281.

220. Fritzenwanker JH, Genikhovich G, Kraus Y, Technau U. Early development and axis specification in the sea anemone Nematostella vectensis. Dev Biol. 2007;310(2):264-79.
221. Fritz AE, Ikmi A, Seidel C, Paulson A, Gibson MC. Mechanisms of tentacle morphogenesis in the sea anemone Nematostella vectensis. Development. 2013;140(10):2212-23.

222. Hand C, Uhlinger KR. Asexual Reproduction by Transverse Fission and Some Anomalies in the Sea Anemone Nematostella vectensis. Invertebr Biol. 1995; 114(1):9-18.

223. Putnam NH, Srivastava M, Hellsten U, Dirks B, Chapman J, Salamov A, et al. Sea anemone genome reveals ancestral eumetazoan gene repertoire and genomic organization. Science. 2007;317(5834):86-94.

224. Sullivan JC, Finnerty JR. A surprising abundance of human disease genes in a simple "basal" animal, the starlet sea anemone (Nematostella vectensis). Genome. 2007;50(7):689-92.

225. Sullivan JC, Reitzel AM, Finnerty JR. A high percentage of introns in human genes were present early in animal evolution: evidence from the basal metazoan Nematostella vectensis. Genome Inf. 2006;17(1):219-29.

226. Sullivan JC, Ryan JF, Watson JA, Webb J, Mullikin JC, Rokhsar D, et al. StellaBase: the Nematostella vectensis Genomics Database. Nucleic Acids Res. 2006;34(Database issue):D495-9.

227. Layden MJ, Rottinger E, Wolenski FS, Gilmore TD, Martindale MQ. Microinjection of mRNA or morpholinos for reverse genetic analysis in the starlet sea anemone, Nematostella vectensis. Nat Protoc. 2013;8(5): 924-34

228. Renfer E, Amon-Hassenzahl A, Steinmetz PR, Technau U. A muscle-specific transgenic reporter line of the sea anemone, Nematostella vectensis. Proc Natl Acad Sci U S A. 2010;107(1):104-8.

229. Nakanishi N, Renfer E, Technau U, Rentzsch F. Nervous systems of the sea anemone Nematostella vectensis are generated by ectoderm and endoderm and shaped by distinct mechanisms. Development. 2012; 139(2):347-57.

230. Layden MJ, Johnston H, Amiel AR, Havrilak J, Steinworth B, Chock T, et al, MAPK signaling is necessary for neurogenesis in Nematostella vectensis. BMC Biol. 2016;14:61.

231. Schwaiger M, Schonauer A, Rendeiro AF, Pribitzer C, Schauer A, Gilles AF, et al. Evolutionary conservation of the eumetazoan gene regulatory landscape. Genome Res. 2014;24(4):639-50.

232. Ikmi A, McKinney SA, Delventhal KM, Gibson MC. TALEN and CRISPR/Cas9mediated genome editing in the early-branching metazoan Nematostella vectensis. Nat Commun. 2014;5:5486.

233. Kraus Y, Aman A, Technau U, Genikhovich G. Pre-bilaterian origin of the blastoporal axial organizer. Nat Commun. 2016;7:11694.

234. Kusserow A, Pang K, Sturm C, Hrouda M, Lentfer J, Schmidt HA, et al. Unexpected complexity of the Wnt gene family in a sea anemone. Nature. 2005:433(7022):156-60.

235. Leclere L, Rentzsch F. RGM regulates BMP-mediated secondary axis formation in the sea anemone Nematostella vectensis. Cell Rep. 2014:9(5):1921-30.

236. Hudry B, Thomas-Chollier M, Volovik Y, Duffraisse M, Dard A, Frank D, et al. Molecular insights into the origin of the Hox-TALE patterning system. Elife. 2014;3:e01939.

237. Magie CR, Daly M, Martindale MQ. Gastrulation in the cnidarian Nematostella vectensis occurs via invagination not ingression. Dev Biol. 2007;305(2):483-97.

238. Martindale MQ, Pang K, Finnerty JR. Investigating the origins of triploblasty: "mesodermal" gene expression in a diploblastic animal, the sea anemone Nematostella vectensis (phylum, Cnidaria; class, Anthozoa). Development. 2004;131(10):2463-74.

239. Layden MJ, Boekhout M, Martindale MQ. Nematostella vectensis achaetescute homolog NvashA regulates embryonic ectodermal neurogenesis and represents an ancient component of the metazoan neural specification pathway. Development. 2012;139(5):1013-22.

240. Richards GS, Rentzsch F. Regulation of Nematostella neural progenitors by SoxB, Notch and bHLH genes. Development. 2015;142(19):3332-42.

241. Baumgarten S, Simakov O, Esherick LY, Liew YJ, Lehnert EM, Michell CT, et al. The genome of Aiptasia, a sea anemone model for coral symbiosis. Proc Natl Acad Sci U S A. 2015;112(38):11893-8.

242. Yasuoka Y, Shinzato C, Satoh N. The Mesoderm-Forming Gene brachyury Regulates Ectoderm-Endoderm Demarcation in the Coral Acropora digitifera. Curr Biol. 2016;26(21):2885-92

243. Plickert G, Frank U, Muller WA. Hydractinia, a pioneering model for stem cell biology and reprogramming somatic cells to pluripotency. Int J Dev Biol. 2012;56(6-8):519-34

244. Houliston E, Momose T, Manuel M. Clytia hemisphaerica: a jellyfish cousin joins the laboratory. Trends Genet. 2010;26(4):159-67. 
245. Aguinaldo AM, Turbeville JM, Linford LS, Rivera MC, Garey JR, Raff RA, et al. Evidence for a clade of nematodes, arthropods and other moulting animals. Nature. 1997;387:489-93.

246. Gabriel WN, McNuff R, Patel SK, Gregory TR, Jeck WR, Jones CD, et al. The tardigrade Hypsibius dujardini, a new model for studying the evolution of development. Dev Biol. 2007;312(2):545-59.

247. Altiero T, Rebecchi L. Rearing tardigrades: Results and problems. Zool Anz. 2001;240(3-4):217-21.

248. Blaxter M, Elsworth B, Daub J. DNA taxonomy of a neglected animal phylum: an unexpected diversity of tardigrades. Proc Biol Sci. 2004;271(Suppl):S189-92.

249. Gabriel WN, Goldstein B. Segmental expression of Pax3/7 and Engrailed homologs in tardigrade development. Dev Genes Evol. 2007;217(6):421-33.

250. Tenlen JR, McCaskill S, Goldstein B. RNA interference can be used to disrupt gene function in tardigrades. Dev Genes Evol. 2013;223(3):171-81.

251. Smith FW, Boothby TC, Giovannini I, Rebecchi L, Jockusch EL, Goldstein B. The Compact Body Plan of Tardigrades Evolved by the Loss of a Large Body Region. Curr Biol. 2016;26(2):224-9.

252. Maderspacher F. Zoology: The Walking Heads. Curr Biol. 2016;26(5):R194-7.

253. Watanabe M. Anhydrobiosis in invertebrates. Appl Entomol Zool. 2006; $41(1): 15-31$

254. Møbjerg N, Halberg KA, Jørgensen A, Persson D, Bjørn M, Ramløv H, et al. Survival in extreme environments - on the current knowledge of adaptations in tardigrades. Acta Physiol. 2011;202(3):409-20.

255. Jönsson Kl, Rabbow E, Schill RO, Harms-Ringdahl M, Rettberg P. Tardigrades survive exposure to space in low Earth orbit. Curr Biol. 2008;18(17):R729-31.

256. Rebecchi L, Altiero T, Guidetti R, Cesari M, Bertolani R, Negroni M, et al. Tardigrade Resistance to Space Effects: First Results of Experiments on the LIFE-TARSE Mission on FOTON-M3 (September 2007). Astrobiology. 2009;9(6):581-91.

257. Boothby T, Tapia H, Brozena AH, Piszkiewicz S, Smith AE, Giovannini I. Tardigrades Use Intrinsically Disordered Proteins to Survive Desiccation. Mol Cell. 2017;65(6):In Press.

258. Hashimoto T, Horikawa DD, Saito Y, Kuwahara H, Kozuka-Hata H, Shin-I T, et al. Extremotolerant tardigrade genome and improved radiotolerance of human cultured cells by tardigrade-unique protein. Nat Commun. 2016;7:12808.

259. Yoshida Y, Koutsovoulos G, Laetsch DR, Stevens L, Kumar S, Horikawa DD, et al. Comparative genomics of the tardigrades Hypsibius dujardini and Ramazzottius varieornatus. bioRxiv. 2017;112664. https://doi.org/10.1101/ 112664.

260. Goldstein B, King N. The Future of Cell Biology: Emerging Model Organisms. Trends Cell Biol. 2016;26(11):818-24

261. Stocum DL. The urodele limb regeneration blastema: a self-organizing system. I. Morphogenesis and differentiation of autografted whole and fractional blastemas. Dev Biol. 1968;18(5):457-80.

262. Iten LE, Bryant SV. Regeneration from different levels along the tail of the newt, Notophthalmus viridescens. J Exp Zool. 1976;196(3):293-306.

263. Dunis DA, Namenwirth $M$. The role of grafted skin in the regeneration of $X$ irradiated axolotl limbs. Dev Biol. 1977:56(1):97-109.

264. Sobkow L, Epperlein HH, Herklotz S, Straube WL, Tanaka EM. A germline GFP transgenic axolotl and its use to track cell fate: Dual origin of the fin mesenchyme during development and the fate of blood cells during regeneration. Dev Biol. 2006;290(2):386-97.

265. Khattak S, Schuez M, Richter T, Knapp D, Haigo SL, Sandoval-Guzmán T, et al. Germline transgenic methods for tracking cells and testing gene function during regeneration in the axolotl. Stem Cell Reports. 2013;1 (1):90-103.

266. Whited JL, Lehoczky JA, Tabin CJ. Inducible genetic system for the axolotl. Proc Natl Acad Sci U S A. 2012;109(34):13662-7.

267. Flowers GP, Timberlake AT, McLean KC, Monaghan JR, Crews CM. Highly efficient targeted mutagenesis in axolotl using Cas9 RNA-guided nuclease. Development. 2014;141(10):2165-71.

268. Fei JF, Schuez M, Tazaki A, Taniguchi Y, Roensch K, Tanaka EM. CRISPRmediated genomic deletion of Sox2 in the axolotl shows a requirement in spinal cord neural stem cell amplification during tail regeneration. Stem Cell Rep. 2014;3(3):444-59.

269. Roy S, Gardiner DM, Bryant SV. Vaccinia as a Tool for Functional Analysis in Regenerating Limbs: Ectopic Expression of Shh. Dev Biol. 2000;218(2):199-205.

270. Whited JL, Tsai SL, Beier KT, White JN, Piekarski N, Hanken J, et al. Pseudotyped retroviruses for infecting axolotl in vivo and in vitro. Development. 2013;140(5):1137-46.

271. Khattak S, Sandoval-Guzmán T, Stanke N, Protze S, Tanaka EM, Lindemann D. Foamy virus for efficient gene transfer in regeneration studies. BMC Dev Biol. 2013;13(1):1-9.
272. Nacu E, Gromberg E, Oliveira CR, Drechsel D, Tanaka EM. FGF8 and SHH substitute for anterior-posterior tissue interactions to induce limb regeneration. Nature. 2016;1(7603):1-16.

273. Echeverri K, Tanaka EM. Electroporation as a tool to study in vivo spinal cord regeneration. Dev Dyn. 2003;226(2):418-25.

274. Hayashi T, Sakamoto K, Sakuma T, Yokotani N, Inoue T, Kawaguchi E, et al. Transcription activator-like effector nucleases efficiently disrupt the target gene in Iberian ribbed newts (Pleurodeles waltl), an experimental model animal for regeneration. Dev Growth Differ. 2014;56(1):115-21.

275. Maki N, Suetsugu-Maki R, Sano S, Nakamura K, Nishimura O, Tarui H, et al. Oocyte-type linker histone B4 is required for transdifferentiation of somatic cells in vivo. FASEB J. 2010;24(9):3462-7.

276. Kumar A, Godwin JW, Gates PB, Garza-Garcia AA, Brockes JP. Molecular Basis for the Nerve Dependence of Limb Regeneration in an Adult Vertebrate. Science. 2007;318(5851):772-7.

277. Wang H, Lööf S, Borg P, Nader GA, Blau HM, Simon A. Turning terminally differentiated skeletal muscle cells into regenerative progenitors. Nat Commun. 2015;6:7916.

278. Sandoval-Guzmán T, Wang H, Khattak S, Schuez M, Roensch K, Nacu E, et al. Fundamental differences in dedifferentiation and stem cell recruitment during skeletal muscle regeneration in two salamander species. Cell Stem Cell. 2014;14(2):174-87.

279. Butlera PG, Wanamaker Jr AD, Scoursea JD, Richardson CA, Reynolds AP. Variability of marine climate on the North Icelandic Shelf in a 1357-year proxy archive based on growth increments in the bivalve Arctica islandica. Palaeogeogr Palaeoclimatol Palaeoecol. 2013;373:141-51.

280. Helfand SL, Rogina B. Genetics of aging in the fruit fly, Drosophila melanogaster. Annu Rev Genet. 2003;37:329-48.

281. Olsen A, Vantipalli MC, Lithgow GJ. Using Caenorhabditis elegans as a model for aging and age-related diseases. Ann NY Acad Sci. 2006;1067:120-8.

282. Kaeberlein M, Burtner CR, Kennedy BK. Recent developments in yeast aging PLoS Genet. 2007;3(5), e84.

283. Weyand CM, Goronzy JJ. Aging of the Immune System. Mechanisms and Therapeutic Targets. Ann Am Thorac Soc. 2016;13(Supplement_5):S422-8.

284. Monti D, Ostan R, Borelli V, Castellani G, Franceschi C. Inflammaging and human longevity in the omics era. Mech Ageing Dev. 2016;

285. Miller RA, Harper JM, Dysko RC, Durkee SJ, Austad SN. Longer life spans and delayed maturation in wild-derived mice. Exp Biol Med. 2002;227(7):500-8.

286. Gerhard GS, Kauffman EJ, Wang X, Stewart R, Moore JL, Kasales CJ, et al. Life spans and senescent phenotypes in two strains of Zebrafish (Danio rerio). Exp Gerontol. 2002;37(8-9):1055-68.

287. Valenzano DR, Sharp S, Brunet A. Transposon-Mediated Transgenesis in the Short-Lived African Killifish Nothobranchius furzeri, a Vertebrate Model for Aging. G3. 2011;1(7):531-8.

288. Valenzano DR, Benayoun BA, Singh PP, Zhang E, Etter PD, Hu CK, et al. The African Turquoise Killifish Genome Provides Insights into Evolution and Genetic Architecture of Lifespan. Cell. 2015:163(6):1539-54.

289. Reichwald K, Petzold A, Koch P, Downie BR, Hartmann N, Pietsch S, et al. Insights into Sex Chromosome Evolution and Aging from the Genome of a Short-Lived Fish. Cell. 2015;163(6):1527-38.

290. Valdesalici S, Cellerino A. Extremely short lifespan in the annual fish Nothobranchius furzeri. Proc Biol Sci. 2003;270(Suppl):S189-91.

291. Kirschner J, Weber D, Neuschl C, Franke A, Bottger M, Zielke L, et al. Mapping of quantitative trait loci controlling lifespan in the short-lived fish Nothobranchius furzeri-a new vertebrate model for age research. Aging Cell. 2012;11(2):252-61.

292. Valenzano DR, Kirschner J, Kamber RA, Zhang E, Weber D, Cellerino A, et al. Mapping loci associated with tail color and sex determination in the shortlived fish Nothobranchius furzeri. Genetics. 2009;183(4):1385-95.

293. Harel I, Valenzano DR, Brunet A. Efficient genome engineering approaches for the short-lived African turquoise killifish. Nat Protoc. 2016;11(10):2010-28.

294. Polacik M, Blazek R, Reichard M. Laboratory breeding of the short-lived annual killifish Nothobranchius furzeri. Nat Protoc. 2016;11(8):1396-413.

295. Di Cicco E, Tozzini ET, Rossi G, Cellerino A. The short-lived annual fish Nothobranchius furzeri shows a typical teleost aging process reinforced by high incidence of age-dependent neoplasias. Exp Gerontol. 2011;46(4):249-56.

296. Valenzano DR, Terzibasi E, Cattaneo A, Domenici L, Cellerino A. Temperature affects longevity and age-related locomotor and cognitive decay in the short-lived fish Nothobranchius furzeri. Aging Cell. 2006:5(3):275-8.

297. Wendler S, Hartmann N, Hoppe B, Englert C. Age-dependent decline in fin regenerative capacity in the short-lived fish Nothobranchius furzeri. Aging Cell. 2015;14(5):857-66. 
298. Bartakova V, Reichard M, Janko K, Polacik M, Blazek R, Reichwald K, et al. Strong population genetic structuring in an annual fish, Nothobranchius furzeri, suggests multiple savannah refugia in southern Mozambique. BMC Evol Biol. 2013;13:196.

299. Furness Al. The evolution of an annual life cycle in killifish: adaptation to ephemeral aquatic environments through embryonic diapause. Biol Rev Camb Philos Soc. 2016;91(3):796-812.

300. Polacik M, Blazek R, Rezucha R, Vrtilek M, Terzibasi Tozzini E, Reichard M. Alternative intrapopulation life-history strategies and their trade-offs in an African annual fish. J Evol Biol. 2014;27(5):854-65.

301. Parle R. Two new Nothos from Rhodesia. AKA Kill Notes. 1970;3(6):15-21.

302. Harel I, Brunet A. The African Turquoise Killifish: A Model for Exploring Vertebrate Aging and Diseases in the Fast Lane. Cold Spring Harb Symp Quant Biol. 2015;80:275-9.

303. Kim Y, Nam HG, Valenzano DR. The short-lived African turquoise killifish: an emerging experimental model for ageing. Dis Model Mech. 2016;9(2):115-29.

304. Platzer M, Englert C. Nothobranchius furzeri: A Model for Aging Research and More. Trends Genet. 2016:32(9):543-52.

305. Cellerino A, Valenzano DR, Reichard M. From the bush to the bench: the annual Nothobranchius fishes as a new model system in biology. Biol Rev Camb Philos Soc. 2016;91(2):511-33.

306. Stanford African Turquoise Killifish Genome Browser. http:// africanturquoisekillifishbrowser.org/. Accessed 3 Mar 2017.

307. FLI Nothobranchius furzeri Genome Browser. http://nfingb.leibniz-fli.de/.

308. Baumgart M, Groth M, Priebe S, Savino A, Testa G, Dix A, et al. RNA-seq of the aging brain in the short-lived fish $\mathrm{N}$. furzeri - conserved pathways and novel genes associated with neurogenesis. Aging Cell. 2014;13(6):965-74.

309. Baumgart M, Groth M, Priebe S, Appelt J, Guthke R, Platzer M, et al. Agedependent regulation of tumor-related microRNAs in the brain of the annual fish Nothobranchius furzeri. Mech Ageing Dev. 2012;133(5):226-33.

310. D’Angelo L, De Girolamo P, Lucini C, Terzibasi ET, Baumgart M, Castaldo L, et al. Brain-derived neurotrophic factor: mRNA expression and protein distribution in the brain of the teleost Nothobranchius furzeri. J Comp Neurol. 2014;522(5):1004-30.

311. Ng'oma E, Groth M, Ripa R, Platzer M, Cellerino A. Transcriptome profiling of natural dichromatism in the annual fishes Nothobranchius furzeri and Nothobranchius kadleci. BMC Genomics. 2014;15:754.

312. Petzold A, Reichwald K, Groth M, Taudien S, Hartmann N, Priebe S, et al. The transcript catalogue of the short-lived fish Nothobranchius furzeri provides insights into age-dependent changes of mRNA levels. BMC Genomics. 2013;14:185.

313. Baumgart M, Priebe S, Groth M, Hartmann N, Menzel U, Pandolfini $L$, et al. Longitudinal RNA-Seq Analysis of Vertebrate Aging Identifies Mitochondrial Complex I as a Small-Molecule-Sensitive Modifier of Lifespan. Cell Syst. 2016; 2(2):122-32.

314. NCBI Reference Genome-Nothobranchius furzeri. https://www.ncbi.nlm.nih. gov/genome/2642.

315. Meenakumari KJ, Krishna A. Delayed embryonic development in the Indian short-nosed fruit bat, Cynopterus sphinx. Zool. 2005;108(2):131-40.

316. Bleier WJ. Early embryology and implantation in the California leaf-nosed bat, Macrotus californicus. Anat Rec. 1975;182(2):237-53.

317. Frezal L, Felix MA. C. elegans outside the Petri dish. Elife. 2015;4, e05849.

318. Fielenbach N, Antebi A. C. elegans dauer formation and the molecular basis of plasticity. Genes Dev. 2008;22(16):2149-65.

319. Murphy CT. The search for DAF-16/FOXO transcriptional targets: approaches and discoveries. Exp Gerontol. 2006:41(10):910-21.

320. Zhao X, Bergland AO, Behrman EL, Gregory BD, Petrov DA, Schmidt PS. Global Transcriptional Profiling of Diapause and Climatic Adaptation in Drosophila melanogaster. Mol Biol Evol. 2016;33(3):707-20.

321. Kucerova L, Kubrak OI, Bengtsson JM, Strnad H, Nylin S, Theopold U, et al. Slowed aging during reproductive dormancy is reflected in genome-wide transcriptome changes in Drosophila melanogaster. BMC Genomics. 2016;17:50

322. Klass M, Hirsh D. Non-ageing developmental variant of Caenorhabditis elegans. Nature. 1976;260(5551):523-5.

323. Roux AE, Langhans K, Huynh W, Kenyon C. Reversible Age-Related Phenotypes Induced during Larval Quiescence in C. elegans. Cell Metab. 2016;23(6):1113-26.

324. Amin SA, Parker MS, Armbrust EV. Interactions between diatoms and bacteria. Microbiol Mol Biol Rev. 2012;76(3):667-84

325. Vogt A, Goldman AD, Mochizuki K, Landweber LF. Transposon Domestication versus Mutualism in Ciliate Genome Rearrangements. PLoS Genetics. 2013;9(8), e1003659.
326. Schierwater B, Eitel M, Jakob W, Osigus HJ, Hadrys H, Dellaporta SL, et al. Concatenated analysis sheds light on early metazoan evolution and fuels a modern "urmetazoon" hypothesis. PLoS Biol. 2009;7(1), e20.

327. Jekely G, Paps J, Nielsen C. The phylogenetic position of ctenophores and the origin(s) of nervous systems. Evodevo. 2015;6:1.

328. Goss RJ. Principles of Regeneration. USA: Elsevier Books; 1969. 